\title{
Typologies of the popular science web video
}

\section{Jesús Muñoz Morcillo, Klemens Czurda and Caroline Y. Robertson-von Trotha}

\begin{abstract}
This article provides a first statistical analysis of the typologies and characteristics of popular science web videos on YouTube. An analysis of 190 videos from 95 online video channels was conducted. Several factors such as narrative strategies, video editing techniques, and design tendencies with regard to cinematography, the number of shots, the kind of montage used, and even the use of sound design and special FX point to a notable professionalism among science communicators independent of institutional or personal commitments. This analysis represents an important step in understanding the essence of current popular science web videos and provides an evidence-based description of their distinctive features.
\end{abstract}

Keywords

Popularization of science and technology; Science and media; Visual communication

Since the creation of YouTube in 2005, there have been opposing positions on the quality of web videos. Some criticize the banality displayed by the majority of amateur movies on the Internet [Keen, 2007, p. 5; Lovink, 2011, p. 9], while others praise the participatory culture fostered by this new mass media phenomenon [Jenkins, 2006; Hartley, 2009]. Today, there is a broad consensus that most videos on the Internet involve familiar or commonplace contents [Marek, 2013, p. 17]. However, there are some exceptions. One of them is the "popular science web video". A popular science web video is a short video that focuses on the communication of scientific contents for a broad audience on the Internet. For the sake of terminological simplicity and easier reading, in the following we will speak of "science web video" or "science video", referring to the above definition. A set of science videos uploaded by one user constitutes an online video channel. Video channels that make scientific knowledge accessible to the public are the subject of the present study. Up until now, the global phenomenon of science communication on YouTube have seldom been subject to statistical analysis. Apart from a study on the popularity factors that rule science communication on YouTube [Welbourne and Grant, 2015a] there are some publications concerning the relation between popularity and veracity [e.g. Keelan et al., 2007; Sood et al., 2011], accuracy of scientific content [e.g. Backinger et al., 2010; Steinberg et al., 2010] and the difference between User Generated Content (UGC) and Professional Generated Content (PGC) [e.g. Lo, Esser and Gordon, 2010] on single scientific topics. A 
special mention deserves the review of methods for studying YouTube videos on health and medicine topics made by Sampson et al. [2013]: even if this publication focuses on a meta-level for analyzing methods used in reviews of YouTube health videos it is a good state of the art on health and medicine communication on YouTube. Against this background, the analysis made by Welbourne and Grant [2015a] sticks out as the first description of popularity factors of science web videos based on a reliable statistical analysis regardless of a main scientific topic. However, no one has yet brought into focus the main narrative characteristics, aesthetics, and production context of popular science web videos. These issues constitute the fundamentals for a content oriented analysis of science communication on YouTube beyond the general question of popularity factors, since these are very similar in most web video productions. Indeed, the results of Welbourne et al. are in accordance with the most common advice YouTubers and bloggers give as recommendation for a successful video channel. This lack of focus on the actual characteristics of science communication via online videos is all the more surprising as YouTube - the most popular online video platform with more than 4,000 science channels and 100,000 science videos [Yang and Qian, 2011] [ $^{1}$ presents itself as a highly visible, varied, and growing data corpus with worldwide accessibility.

From the viewpoint of science and technology studies, which examine inter alia the impact of new media on science communication [cf. Bucchi, 1998; Bucchi and Trench, 2008; Robertson-von Trotha and Muñoz Morcillo, 2012], some key questions arise: what are the main characteristics of popular science web videos? Who is communicating science through these videos, and for what purpose? And how are these videos related to the main characteristics of the overall phenomenon of video communication on the Internet?

The following analysis of 190 web videos provides a general typology of the global operating tendencies of science and educational video channels on the Internet. This is meant to constitute a first step for further investigations on this particular form of the web video, its production context, and its importance for science communication. The main goals of our analysis are: (1) the identification of the most popular science video channels and their producers according to the findings of the YouTube search algorithm both worldwide and in each individual country; as an additional criterion, we compare these results with the recommendations of experts on reputable online science blogs; (2) producing a typological study on aesthetic and narrative trends on science web videos for the public; and (3) providing an informational basis for future context and network analysis with a focus on the interaction and influence between science videos and their creators on the Internet.

This introduction is followed by an outline of the methodology used, in which the data corpus is defined. Furthermore, we present a description of the analysis carried out by means of a standardized codebook. Finally, we present our findings and the conclusions drawn from them, providing an outlook on possible future research.

\footnotetext{
${ }^{1}$ According to YouTube's own statistics, there are 300 hours of video content uploaded every minute to the video platform: https://www.youtube.com/yt/press/statistics.html (visited on 18 March 2015).

${ }^{2}$ YouTube is a methodological choice that forms the basis for our data collection.
} 
We sampled 190 videos from 95 video channels related to science and education published on the Google-owned website YouTube. For the selection of popular science web videos we first examined the organizational structure of YouTube at the moment of the data collection. Following this contextual information as an orientation, we used the "worldwide" list at the YouTube channel category site "Science \& Education" and selected the most popular channels from 77 different localizations. The selection of science web video channels on YouTube was supplemented by information that we retrieved from highly frequented science blogs. Some video channels that didn't fit into the definition of "popular science web video" as described in this article were excluded. We collected both general data about the channels and the videos such as title, link, views, and subscribers, and particular data about specific characteristics following standards in film aesthetics and filmmaking. The participants in the analysis were first trained in film aesthetics in order to understand and correctly identify what we were looking for. The team was composed of one trainee (Friederike Shymura), two assistants (Thi Hoai Thuong and Klarissa Niedermeier) and two researchers (Klemens Czurda und Jesús Muñoz Morcillo). For the sake of consistency, a single author (J.M.M.) reviewed all web videos for inclusion.

\section{The organizational structure of YouTube}

To form a methodology analyzing popular scientific web videos, it is first necessary to sketch an outline of YouTube and how it organizes its online appearance. At present, YouTube is the most popular platform for web videos [Alexa, 2015; Quantcast, 2015]. On the front page as well as on the subpages of YouTube, videos are listed as so-called "thumbnails", small images that show a still from or a picture made for the video in question. YouTube displays its content in 77 different localizations ${ }^{3}$ and 61 languages based on the accessing users' IP addresses and browser settings. The localized pages are organized in different thematic sections, called lists. These lists basically consist of channels with uploaded videos. The channels are maintained by user accounts belonging to individuals, groups, companies, or other governmental and non-governmental agencies generally called "YouTubers". As for the video site: a video is separated into the video itself, offering embedded text and links, and the website framing it contains an information area and a comment section with sharing options as well as a voting system consisting of "thumbs up" and "thumbs down" buttons. A channel's popularity and therefore its appearance on the aforementioned lists is not only determined by the generated views, comments, and "likes", but also by the number of subscribed users. All these factors influence the popularity of certain videos, which become economic factors too. Accordingly, many YouTubers make a living out of generating YouTube content. ${ }^{4}$ For the leading YouTube video creators, providing content is a full-time profession.

\footnotetext{
${ }^{3} 1$ worldwide setting and 76 country settings: see the bottom section of https:/ / www.youtube.com/ (visited on 18 March 2015).

${ }^{4}$ In this regard, we analyzed the appearance of subscription requests in the videos or the comment sections of the videos as well as the production background.
} 
Since December 2010, the time limit of first 10 and then 15 minutes was completely removed by YouTube, enabling established users to upload videos of any length. ${ }^{5}$

\section{Selection of popular science web video channels}

For the selection of popular science web video channels, we defined the following steps. First of all, it was necessary to search for suitable YouTube channels with disabled cookies and cleaned cache memory data because these factors can interfere with the reliability of the findings due to search personalization settings and the effects of the so called filter bubble [Pariser, 2011]. For this purpose, we used the "worldwide" list at the YouTube channel category site "Science \& Education". ${ }^{6}$ This site works with an algorithm that takes not only views and subscription numbers into account, but also user engagement - at least since the end of 2012. ${ }^{7}$ This procedure allows the compilation of a global list of popular science channels. The worldwide "Science \& Education" list contains roughly the hundred most popular YouTube videos globally, according to YouTube's own algorithms, which are subject to change. ${ }^{8}$ Second, in order to offer a channel selection of science web videos that is as comprehensive as possible, a comparison of channels by country was required. For this purpose, we searched for the most popular science video channels by country. On YouTube it is possible to choose from among the settings of 76 countries (as of 18 March 2015). As a result, roughly one hundred national and foreign science channels that are popular in the selected country are displayed. These results were compared with the previous YouTube global list of most popular science video channels worldwide in order to achieve a reliable YouTube list of the most popular global operating science channels for the general public. Successful national channels (in Spanish, French, Portuguese, and Italian) were included in the sample of YouTube channels analyzed.

The selection of science web video channels was supplemented by information that we retrieved from highly frequented science blogs. Among these were Open Culture, Getting Smart, Make Use Of, MathsInsider, and others. We identified a total of 63 science blogs by means of Google searches using the following terms: "(best) youtube science channels", "(best) youtube educational channels", "science blog youtube", "recommend(ed) science channels", and the corresponding translations in Spanish, French, Portuguese, and German. We consulted 31 English, 15 Spanish, 13 German, and 4 Portuguese blogs. Expert recommendations enabled us to triangulate our observations and helped us choose the seemingly more impactful channels, in particular with regard to how often a science video channel was mentioned on the listed blog sites.

\footnotetext{
${ }^{5}$ See the official YouTube Blog Post of 12.09.2010: http:/ /youtube-global.blogspot.de/2010/12/up-up-and-away-long-videos-for-more.html (visited on 18 March 2015).

${ }^{6}$ https://www.youtube.com/channels/science_education (visited on 18 March 2015).

${ }^{7}$ See http:/ /youtubecreator.blogspot.de/2012/10/youtube-search-now-optimized-for-time.html (visited on 18 March 2015).

${ }^{8}$ For an automatic statistical representation of the best YouTube videos in the correspondent category can be used YouTube stats sites such as Socialblade (http://socialblade.com/youtube/), Vidstatsx (http:/ / vidstatsx.com) or Socialbakers (http://www.socialbakers.com/statistics/youtube/). These web sites uses the YouTube API for requesting data but differ among other things in the presentation of categories and results by country. In order to create consistency we decided to retrieve our data from the YouTube sites using an empty user profile, i.e. without cookies and cache data.
} 


\section{Limitations of the YouTube search algorithm and network analysis}

The YouTube search algorithm changes from time to time without warning or advance notice in academic publications. Because of this, it is reasonable to contrast the findings on YouTube with an independent source. For this purpose, we consulted specialized Internet sites such as blogs and forum sites, all of which are addressed in this paper as the "blogosphere" for the sake of simplicity.

There are limitations to network-based surveys, in particular when they are based on the study of channel recommendations and video answers (which have since been depreciated by YouTube ${ }^{9}$ ) as indicators of possible aesthetic influences. Channel recommendations are links to specific YouTube channels that are either spoken or appear as clickable text in the video itself or in the web video description. Usually the links direct to a subscription button for the relevant user's channel. For content providers on YouTube, subscriptions by other YouTube users to their channels are vital for their visibility. These self-organized networks primarily provide more visibility to competing channels, and can be taken into account for a description of the function and interaction of science web video networks on YouTube.

In order to detect and make visible not only the main characteristics of the videos but also the possible qualitative influences between them, it was necessary to design the data collection in two different ways: on the one hand, we analyzed the main aesthetic and narrative characteristics that define these videos, such as storytelling complexity and detailed production aspects. On the other hand, we focused on external and non-formal aspects that allow the reconstruction of interaction patterns between the different channels. As an example, we focused on aspects such as chronological factors, the participation of actors (usually scientists) and technical staff (especially at a local or national level) in different channels, cross references, quotes, and so on. Since the main goal of this paper is to describe a typology of the science web video, a thorough social network analysis will be the subject of future studies, although some of the criteria necessary for such an evaluation were already taken into account for data collection such as the number and placement of links and the production background.

\section{Web video corpus and exceptions}

The decision of whether or not a video on YouTube is categorized as "scientific \& educational" is left solely to the uploading user. The uploader-defined categories lead to a loose use of the terms "science" and "education"; we therefore excluded certain channels from the corpus following the guidelines outlined here.

For the present research we defined "science web video" as an edited educational or science web video that addresses a broad audience and tackles topics related to science. For the identification of scientific subjects, we followed the OECD classification of Fields of Science and Technology (FOS). ${ }^{10}$ As a result of this

\footnotetext{
${ }^{9}$ As of September 2013, the "video response" feature is no longer available on YouTube: http:/ /youtubecreator.blogspot.de/2013/08/so-long-video-responsesnext-up-better.html (visited on 18 March 2015).

${ }^{10}$ For further reference, see the Frascati Manual of the OECD here: http:/ / www.oecd.org/science/inno/38235147.pdf (visited on 18 March 2015).
} 
definition, the following channel types were not taken into account: channels with unedited live recorded videos (such as lectures as seen on the MIT-Channel or India NPTEL-Channel as well as MOOCs (Massive Open Online Courses); channels with no more than five of their own uploads; instructional videos (such as tutorials or videos on cosmetic tips); science movies for children; channels containing intriguing information not related to a scientific topic; channels with educational songs; TV science channels (unless they produce original content for the Internet, such as the Discovery Channel or BBC Earth); channels with informational videos on sexuality; channels with spiritual content; channels without their own uploader-generated content; and cooking channels.

The resulting video channel list includes 95 video channels (see Table 2). From every channel we chose the most recent and the most popular video for analysis. In this regard, our study on the typologies of the popular science web video is based on a corpus of 190 web videos.

\section{Data collection and design of coding categories}

For our study we divided data collection in two phases:

1. Collecting general information about the channel: name, link, video account, subscribers, date of account registration, most popular video (name, link, date, views, likes, dislikes, subtitles), and the last uploaded video (name, link, date, views, likes, dislikes, subtitles).

2. Collecting specific data about the particular videos (the most popular and the most recent videos were chosen): aesthetics and narrative characteristics with standardized form sheets; number of actors according to gender; thumbnail (the video preview still) description; estimated age of the actor(s); shooting location; camera work; average number of shots; kind of storyline; genre as well as intro and outro description; special effects (FX) used; light and sound design; type of music; audio quality; and the quality of the narrator's voice. Data related to techniques used in film were collected by a trained team to ensure consistency. Analysis categories were derived from standard filmography guidelines.

In addition, we gathered information about the uploading account such as the user name and the number of views and uploaded videos since the date of registration. We also documented the kind of recommended links, their position on the screen and/or in the description underneath the video, and if these links were additionally spoken by the user or not. Lastly, we posed questions about the production context, e.g. if the video was an individual's work or made by a group of people, and whether or not the video was for profit (which depends on the presence of advertisements before and/or during the video). For detailed information about the coding questionnaire, see appendix Table 1.

The coding categories were attributed following standards in filmmaking and aesthetics [e.g. Korte, 1999; Bordwell and Thompson, 2006; Steinmetz, 2002]. We first introduced all participants in the basic terminology and elaborated a glossary for consulting in case of doubt. For example, we cleared what is the difference 
between a long and a medium shot or a close-up, which depends on the framing of a motive from a long, a medium or a short distance to the main objects or persons involved in the scene. For a better orientation between shots we also provided pictures of them. For a good identification of film genres and subgenres we provided brief descriptions following film standards [Bordwell and Thompson, 2006; Steinmetz, 2002]. Only in the case of the descriptive categories "Live Drawing" and "Live Writing" we preferred a terminology ad hoc in order to avoid misunderstandings between "whiteboard videos" in particular and "animations" in general.

The actors' age was estimated on the base of facial aging features. The results on the estimated age of the actors are not yet discussed since these will be taken into account for a future study on the production context of web videos.

\section{Results}

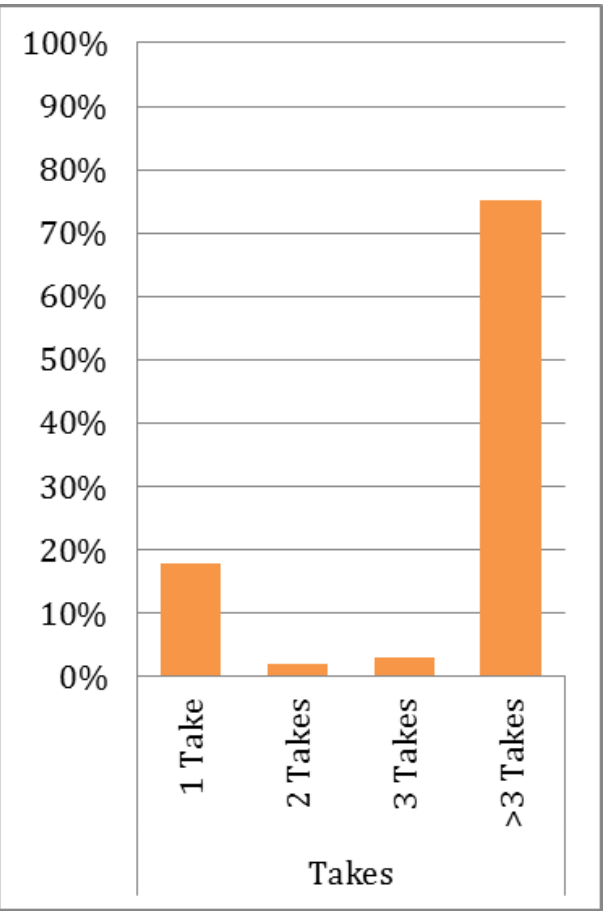

(a)

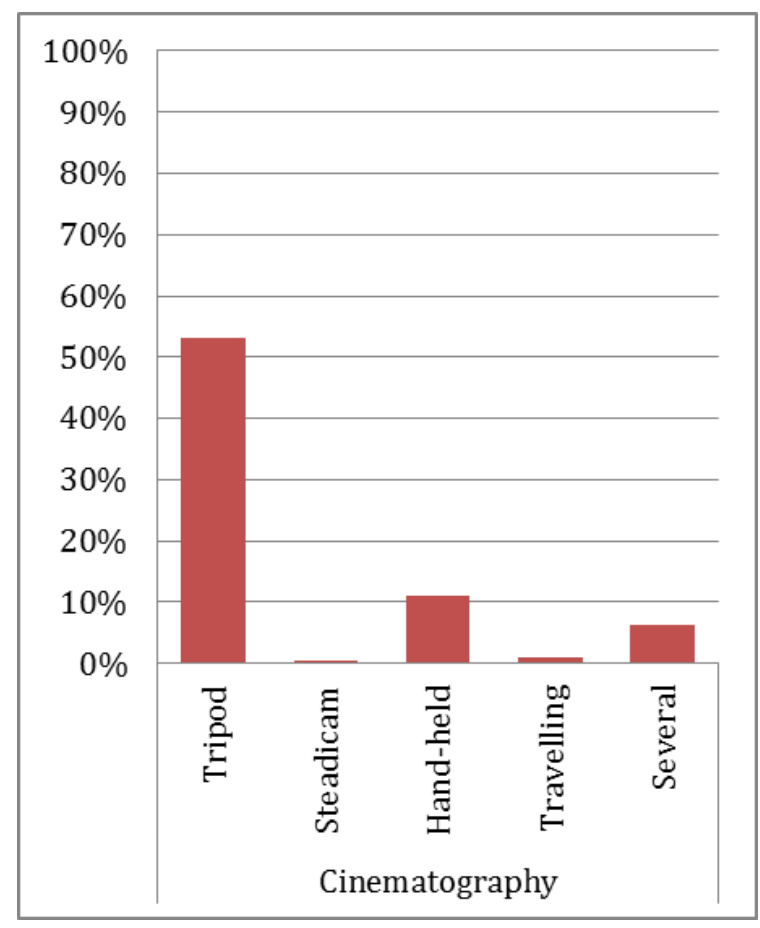

(b)

Figure 1: Number of takes for the production of one video, and cinematographic technique with regard to video camera supporting systems.

\section{Design: montage}

In film, the term "montage" describes the ways filmed material can be put into a coherent, final work. A take is a single, continuous video record (shot). Films and videos usually consist of numerous takes linked together, without gaps, through montage. The use of 3 or more takes can be interpreted as the result of the artist's or director's effort to construct filmic reality through montage. The use of one long take or uninterrupted shot can imply some kind of dramaturgical complexity, but 
since films with long uninterrupted shots are very rare and the video material we examined does not include elaborated long takes, we have to assume that web videos consisting of one take indicate a plain kind of montage. In the following section we will also discuss special effects (FX), an umbrella term for effects added after the video shoot in the post-production phase. Having a post-production phase (including but not limited to montage and FX) is also a sign of sophisticated production, as this requires a special set and level of skills.

Most of the scientific web videos have a deliberate and complex montage: $75 \%$ of them were produced using more than three takes (see Figure 1a). On the other hand, there are interesting examples of scientific web videos that make do with a plan sequence, although in this case other a time lapse (see Figure 11) usually helps to match moving pictures and narration for the sake of a well-paced entertainment.

\section{Design: cinematography}

As for the cinematographic methods (Figure 1b), we see that the most extended technique implies the use of a tripod for stable video recording (53\%).

Nevertheless, many of the most popular science video channels also use hand-held camera aesthetics for the production of their videos (11\%), or combine multiple techniques. Brady Haran (e.g. Sixty Symbols), Derek Muller (e.g. Veritasium), and Destin Sandlin (the maker of Smarter Every Day), who all have extremely popular video channels, belong to the group of hand-held producers.

More elaborate cinematographic techniques such as the use of travelling and steady-cam sequences or other techniques that are usually needed for the production of scenic films are very rare at this stage of development of the scientific web video. These methods of stabilizing the video image are commonplace with professional video outlets such as TV production or cinematic movies but require sophisticated devices and specialized knowledge. A traveling camera means a camera mounted on a movable vehicle (a crane, car, lorry, or dolly system). The Steadicam system (initially developed by cameraman Garret Brown in 1975 and modified for Stanley Kubrick's "The Shining") is a camera stabilizing system where the camera is mounted on the cameraman, allowing swift movement without creating a shaky image. For simplicity, that definition includes gimbal and similar systems in our survey.

\section{Design: shots}

We observed that the amount and variety of shots (Figure 2) resembled the distribution of shots being used in professional documentaries, where medium close-up shots (MCU, for people explaining things) and extreme close-up shots (ECU, for details and objects) also are the favorite ones for explanatory sequences ( $51 \%$ and $38 \%$ respectively). Interesting is the use of close-ups for portraying people $(14 \%)$ in science documentaries and the use of unusual perspectives $(11 \%)$ particularly for fictional spots (e.g. DLR's "DLR crawler robot meets Justin and Hand-Arm-System") and animations (e.g. Wahre Verbrechen.Wahre Stories). This implies, on the one hand, the importance of personal touch for this kind of video production in order to communicate scientific facts to the audience. On the other hand, the use of unusual perspectives denotes the experimental potential that is evolving regarding this new medium on YouTube. 


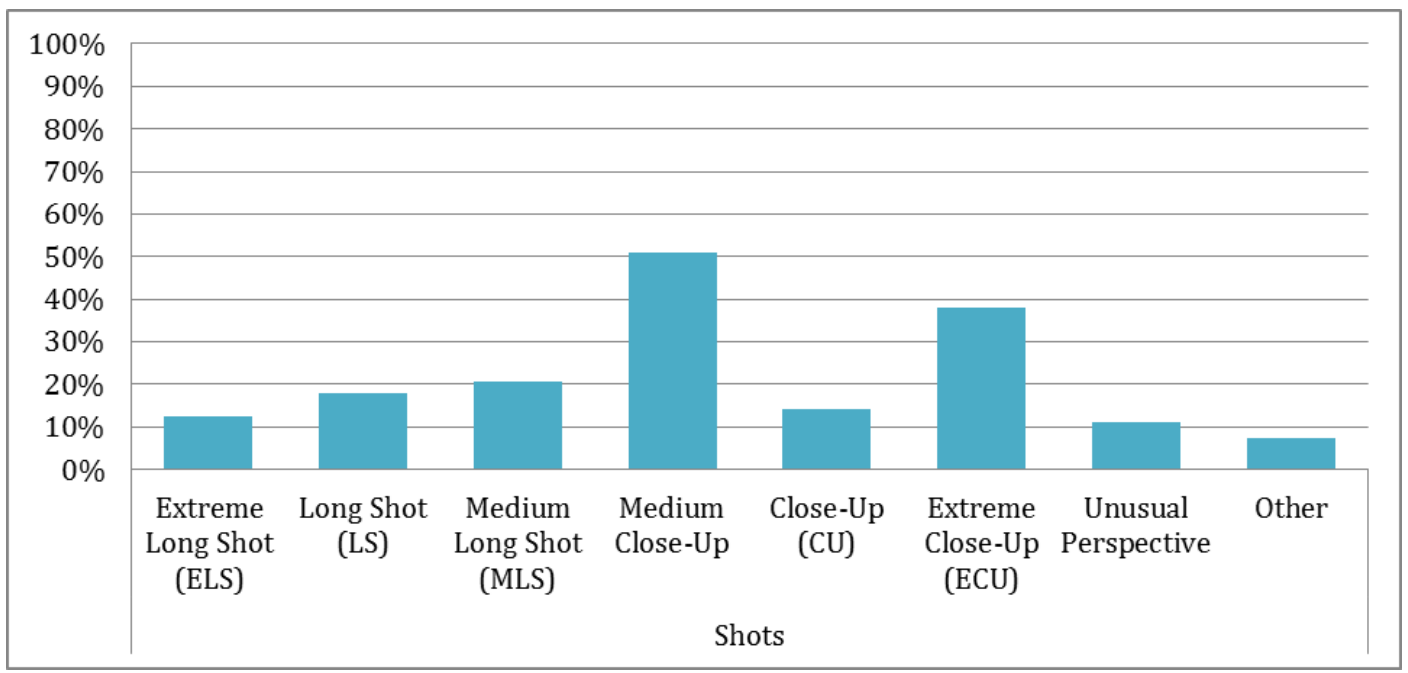

Figure 2: Amount of shots needed for production.

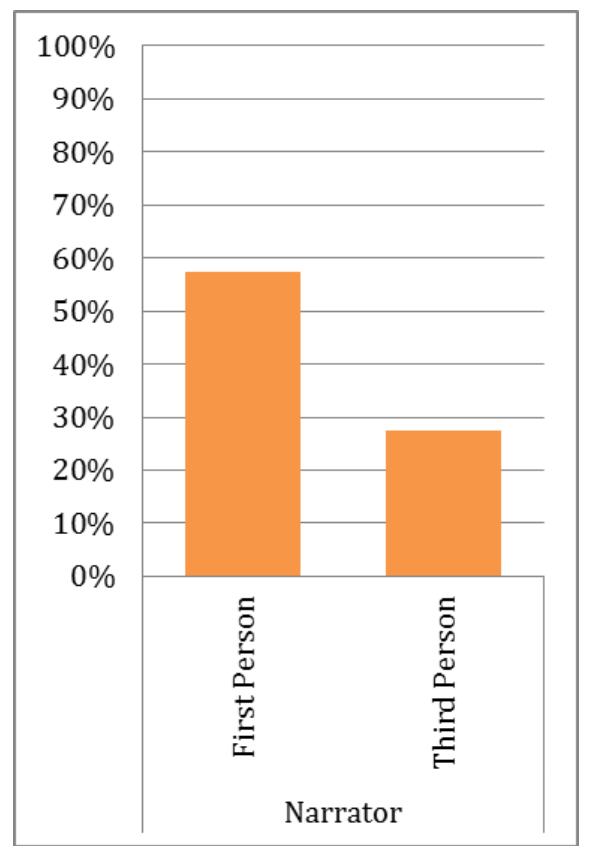

(a)

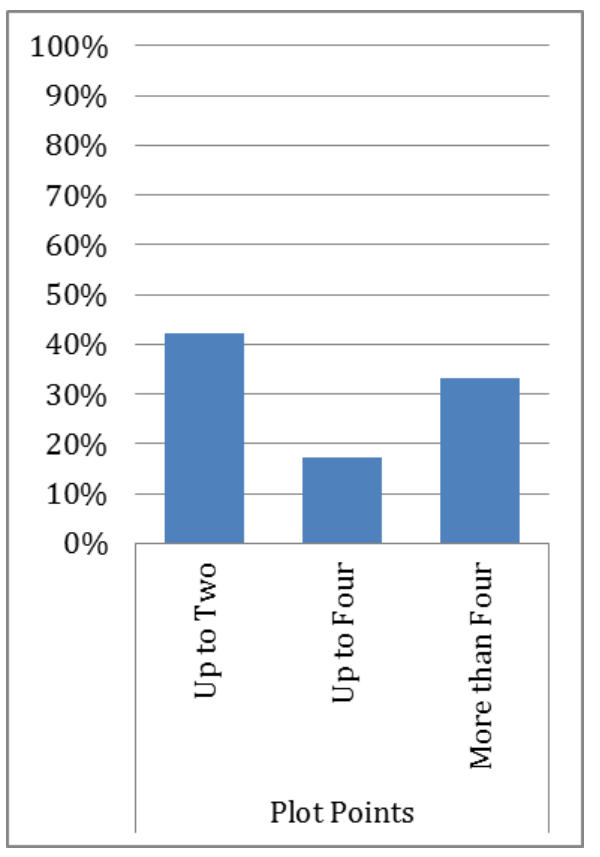

(b)

Figure 3: The use of narrator and the number of plot points for storytelling.

\section{Narrative strategies}

Most of the surveyed scientific web videos (57\%, Figure 3a) used a narration model in the first person, in line with the broad assumption that YouTubers seek to establish a personal connection with the audience wherein the narrator directly addresses viewers. These findings match with the recent study by Welbourne and Grant [Welbourne and Grant, 2015a]: "[...] whether a channel had a regular communicator to deliver content greatly impacted video views".

Nevertheless, about $27 \%$ of the YouTube video channels use a third-person narration model. Here, we have to take into account that more than one third of 
these productions involve animation, so that the use of a narrator as voice-over does not correspond with the structure of typical television documentary. The main motivations for the use of third-person narration seem to be its entertainment value as well as directors' attempts at innovation and originality.

We analyzed plot points (Figure $3 b$ ) to better understand the narrative strategies in scientific web videos. Plot, as a general term for a storyline, can consist of one or multiple plot points. These describe cause-and-effect turns in the narration (such as a point of attack, climax, rising or falling action, etc.). Generally speaking, the more plot points a storyline contains, the more complex it is.

There are many videos that use complex storytelling structures with more than 2 plot points for the development of a "scientific story" (17\% with between 2 and 4 plot points, and over 33\% with more than 4 plot points). Web videos that only need 2 plot points or dramatic forward movements for their "screenplay" are usually explanatory videos ( $>40 \%$ ) that consist of one question and a more or less complex structured answer to it. There can be more than one sub-plot in the answer, such as secondary explanations that lead to the end result. Therefore, even in this case there is a kind of complexity in the "screenplay".

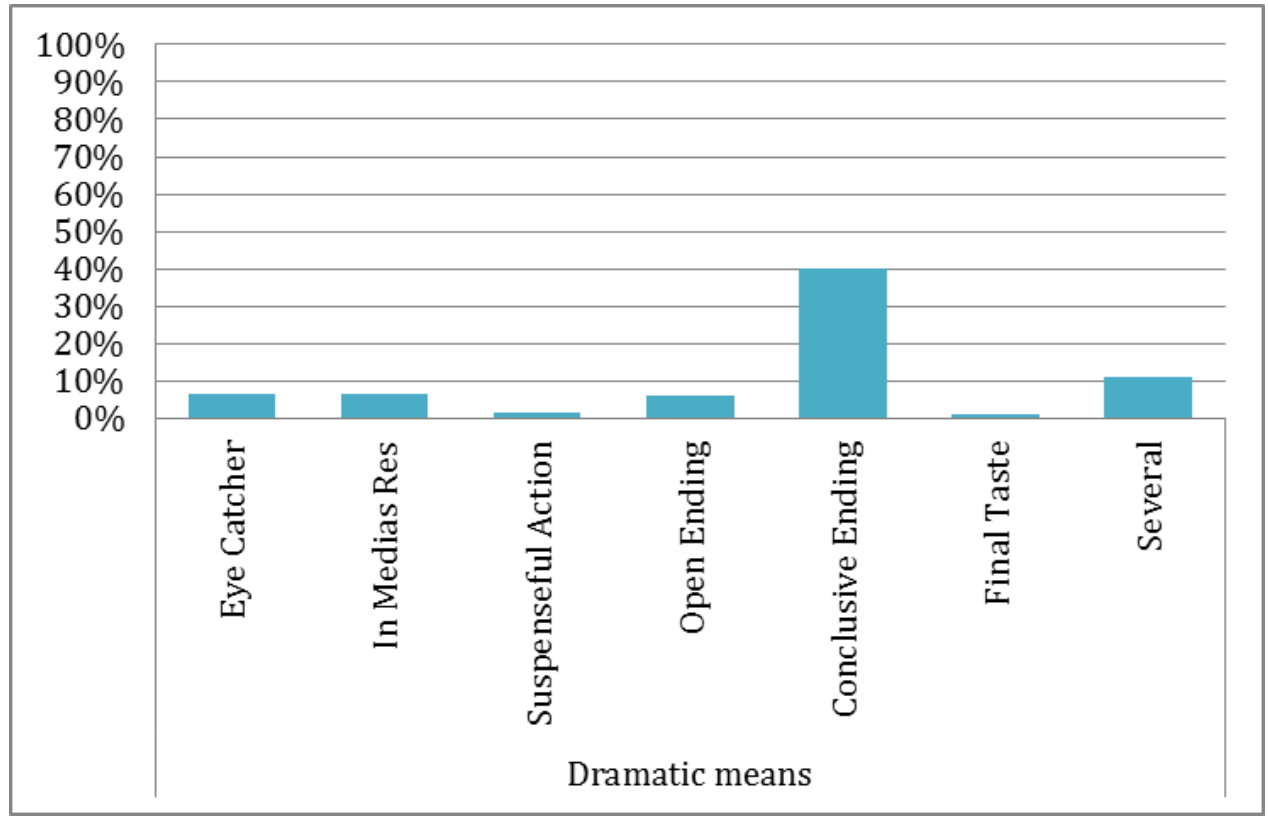

Figure 4: Dramatic means being used in scientific web videos.

The following dramatic means (Figure 4) were analyzed: eye catcher, describing a beginning sequence that immediately tries to get the attention of the viewer; in medias res, which is when a video begins directly in the middle of a narration; suspenseful action, meaning special dramatic happenings; conclusive ending, i.e., a plot point that concludes the content of the video; final taste, which shows a possible outlook or positive notion at the very end of a video; or several of the abovementioned means.

If we take a closer look at the dramatic methods being used, we find a great variety of dramatic means, such as the use of an eye catcher at the beginning of a video $(6 \%)$, in medias res beginnings (6\%), or conclusive endings (40\%). Most of the 
dramatic energy of science web videos to focuses on the climax at the end (40\%), which in many cases is also the answer to the formulated questions. It is remarkable that almost all scientific web videos made by Brady Haran or Derek Muller begin with an eye catcher scene that is followed by the title of the video. Some other very popular YouTubers such as the producers of Vsauce, Smarter every Day, Sixty Symbols, or Veritasium use dramatic elements to create suspenseful action $(2 \%)$, but this method is not very common among the majority of online video educators. These YouTubers - especially those who produce moderated labor films, i.e. with moderation through one or more presenters (e.g. The Spangler Effect), live experiments and scientific demonstrations (e.g. depfisicayquimica), astronomical observations (e.g. TheBadAstronomer), and optical illusions (e.g. Brussup)—appear to be interested in narrating entertaining but very straightforward explanations of scientific facts.

The use of final taste scenes is rare (1\%). A final taste scene is an additional sequence, usually at the very end of a scenic film that provides dramatically irrelevant information in order to leave the audience with a good feeling in case the climax or ending of the film was not very positive. Suspenseful action and final taste scenes usually go together. The same directors tend to use both mechanisms in combination. One probable explanation for the often-observed absence of final taste scenes could be the short duration of most evaluated videos. Another one could be that most of the analyzed web videos don't tackle sensitive social topics.

\section{Genres and subgenres}

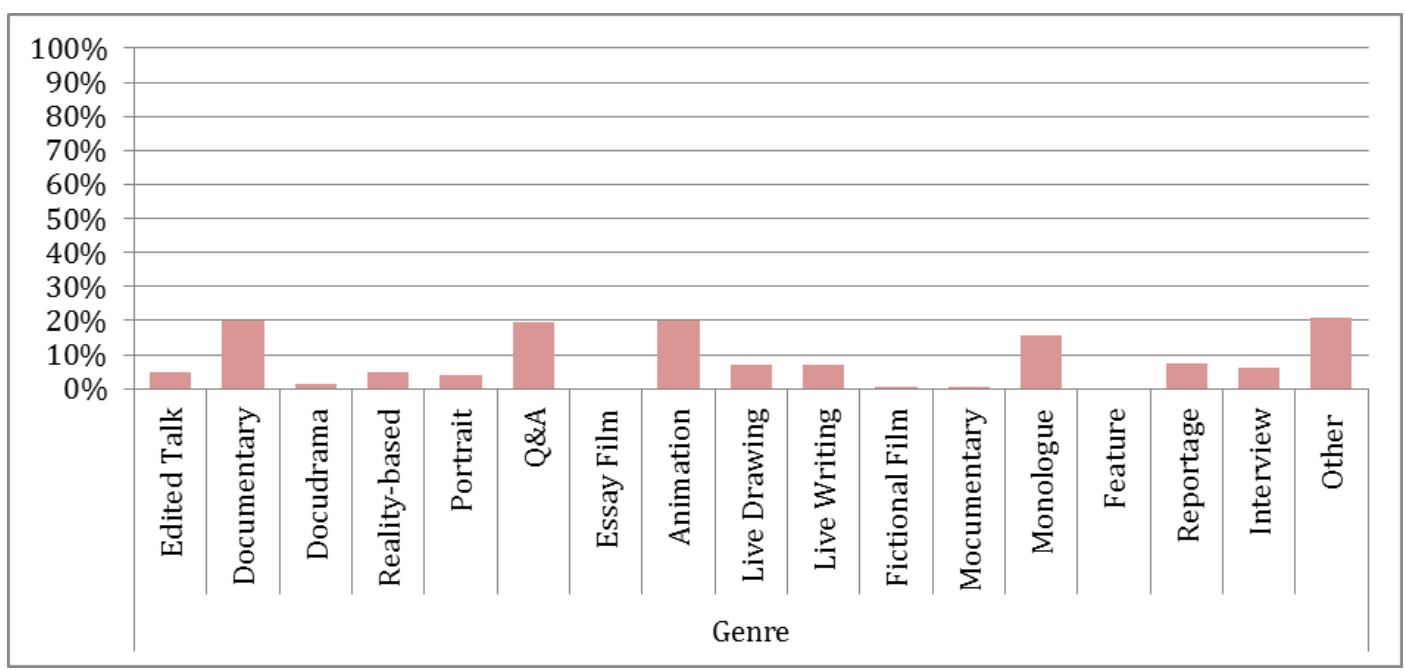

Figure 5: The most popular genres in the production of popular science web videos (multiple choice was possible).

The variety of genres and subgenres in the production of popular science web videos for the public is manifold. As we can see in Figure 5, the most popular genres being used are the short documentary $(20 \%)$ and the animation $(20 \%)$. These classical genres are followed by new subgenres such us entertaining monologues $(16 \%)$ and whiteboard videos (i.e. live drawing, $7 \%$, and live writing, $7 \%$ ). Classical television formats such as interviews $(6 \%)$, and film portraits $(4 \%)$ are also represented in the analyzed video corpus. In the category of reportage $(7 \%)$ we find both very dynamic, innovative videos (e.g. those made by the former BBC reporter 
Brady Haran), and classical TV reportages (e.g. university productions such as those produced by RMIT University). We also noticed that $20 \%$ of the videos have an explanatory structure consisting of a starting question and a more or less straightforward answer: we defined this overlapping category as questions \& answers (Q\&A). The reality-based videos (5\%) build a particular hybrid group of different audiovisual approaches that try to attract the audience's attention through a very strong link to reality. This includes videos based, or pretending to be based, on a real story (e.g. Wahre Verbrechen, Wahre Stories), interactive videos (e.g. matemarika86) as well as videos that claim to be the first ones in their category creating an aura of authenticity (e.g. "First-ever live 3D video stream from space", by ESA).

The edited talk category is used rather infrequently when we look at the numbers $(5 \%)$. However, given the fact that the genre was competing with movie-oriented formats, its turnout is quite impressive. Edited talks thus seem to be a good option for the dissemination of scientific content to a broad audience: in comparison to unedited talks, these videos are mostly short (between 5 and 20 minutes) and focus on the best of the lecture, omitting slow sequences that may occur during a live talk. In addition, edited talks can even fit the lecture into a dramaturgic structure inherent to the speaker's lecture or presentation as well as to the subjective public perspective of the scene.

There is a significant amount of mixed or very specific genres (referred to as "other" in the bar diagram of Figure 5, i.e. 21\%) that demonstrates an experimental trend within the production of popular science web videos. The most significant of them is the moderated "live experiment" $(10 \%)$, as produced by YouTubers such as NurdRage Science Experiments and the SlowMoGuys.

\section{Intros and outros}

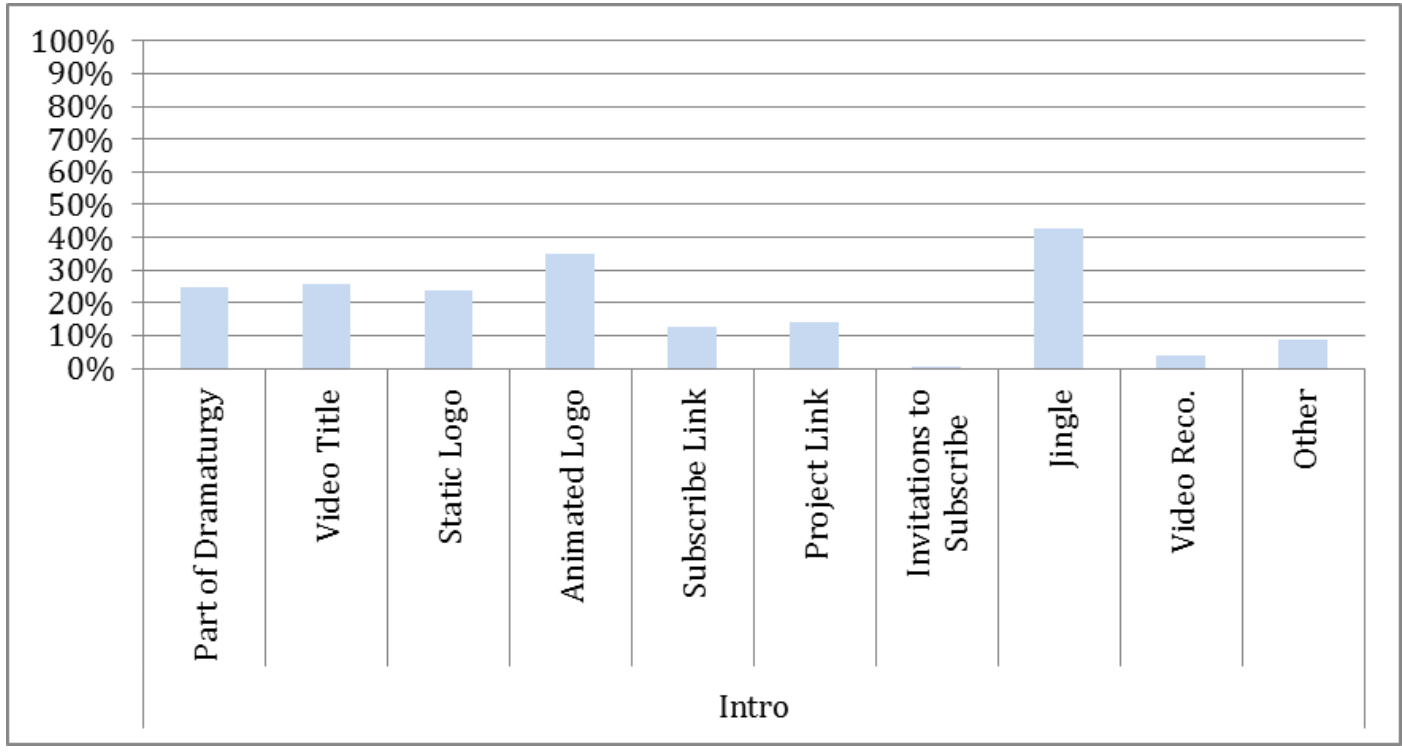

Figure 6: The most common elements used for the construction of intros.

The vast majority of video producers start their videos with a catchy intro. The following main characteristics were identified (Figure 6): most of the videos have a 
characteristic, easy-to-recognize jingle tone (43\%). In a large number of cases $(25 \%)$ the intro sequence is already integrated in the dramaturgy of the film. As in television and cinema movies, the director does not want to waste time or lose the audience, since according to dramatic laws the first ten seconds of a web video is the amount of time you have to convince the audience of the film's entertainment value and scientific quality. In addition to this, it is very common to show the "Corporate Design" of the channel as an animated (35\%) or static logo (24\%) during the intro sequence. It is also interesting to note that not every web video starts with a fade-in title. Only $26 \%$ of them show the title in the intro sequence. Many channels tend to insert the title only in words or even after the intro sequence if this is part of the dramaturgy, and this then functions as an eye catcher or even as the point of attack. Subscribe links and project links are not very common in the intro section, although we did find them in $13 \%$ and $14 \%$ of the analyzed videos respectively. Invitations to subscribe are almost nonexistent.

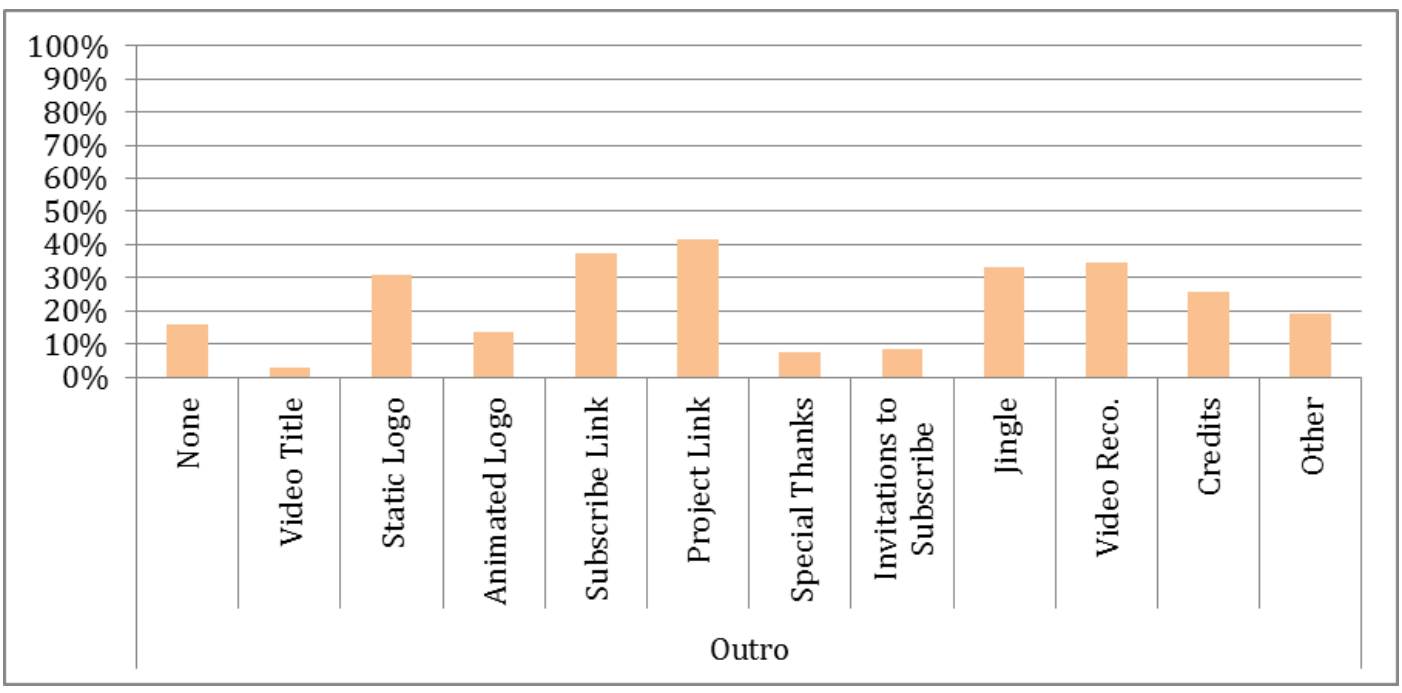

Figure 7: The most common elements used for the construction of outros.

The structure of outro scenes also garnered our attention (Figure 7). We did not find many videos with a subscribe link or an invitation to subscribe at the beginning of them, but in the outro scene this element of community building is more common: subscribe links (37\%), project links (42\%), and even invitations to subscribe $(8 \%)$ are frequently used by YouTubers. The use of animated and static logos as well as a recognizable jingle tones is similar to what is seen in the intro sequence. Credits are not always shown. Many producers abstain from them or release the main information in the searchable description field placed underneath the video. A notable percentage of videos (16\%) did not have an outro. Over $35 \%$ of producers use the outro sequence for the recommendation of other videos.

\section{Special FX}

Special Effects (Special FX, Figure 8) were used in a large number of the videos we examined. Among those are the production of 2- and 3-dimensional animations ( $21 \%$ and $13 \%$ respectively) and their combination ( $7 \%$ ) as well as other less represented film technologies such as augmented reality (AR, 1\%) and green screen (GS, 6\%). Nevertheless, a very significant amount of the video production for 


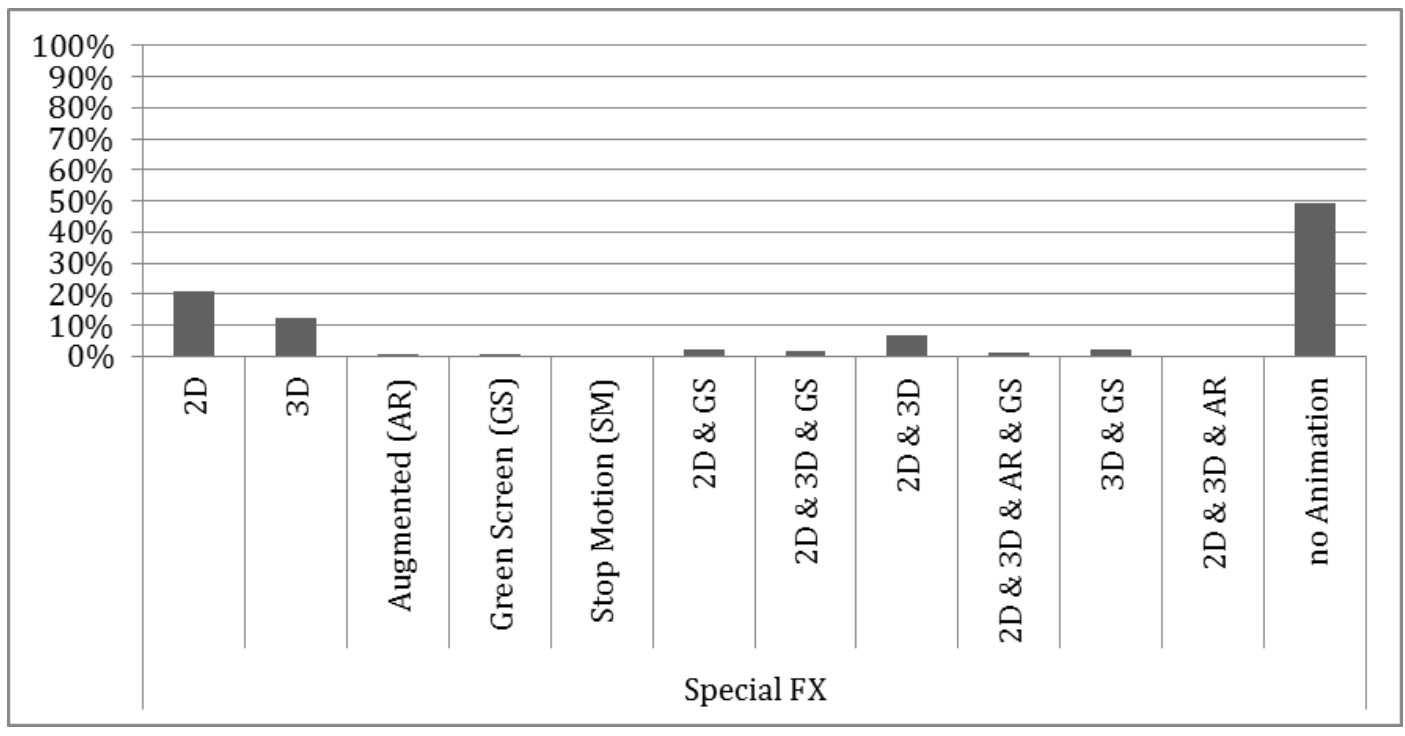

Figure 8: Special FX present in popular scientific videos.

educational or science communication purposes do not make use of any animation techniques (49\%). In this case, the use of simple requisites or costumes constitutes the main trends.

However, if we consider that multiple FX can be used in a single production, the percentage of videos employing Special FX could become significantly smaller. But even in this case, the results indicate that the production of scientific videos for the Internet is to a large extent specialized. This would contradict the general assumption that web videos, even educational ones, are being produced mostly by amateurs [Welbourne and Grant, 2015b; Welbourne and Grant, 2015a].

Although $42 \%$ of the analyzed videos did not use text or picture insertions (Figure 9), we observed that the use of insertions is very recurrent and manifold: insertions of text in picture $(26 \%)$ or picture in picture $(6 \%)$, the use of title slides $(6 \%)$, and the combination of several types of insertions $(20 \%)$ serve as explanatory means for a better communication and clearer understanding of scientific facts. The use of text in picture to create an augmented reality-like composition is the most prevalent method, followed by the combination of this kind of information enhancement with the use of picture in picture. As we can see in some examples such as SmarterEveryDay, SciShow, or Vsauce, the use of picture in picture is qualitatively manifold. While title slides and text insertions focus on additional explanatory values, the use of picture in picture varies depending of the desired goal. In the outro sequences, for example, we are more likely to find picture in picture compositions as means for previews of upcoming content; while in the body sequence, this kind of additional effect has an educational or explanatory function.

Another interesting observation is a significant use of footage material (taken as a whole $48 \%$ ) such as pictures $(15 \%)$, old films $(7 \%)$, or graphics (3\%, Figure 10$)$. This phenomenon is particularly prevalent in video channels that deal with historical scientific facts and news, such as TopZehn, Smarter Every Day, and Vsauce. There are channels that go back to free footage offered by public institutions such as international research centers or universities to quote them in their videos 


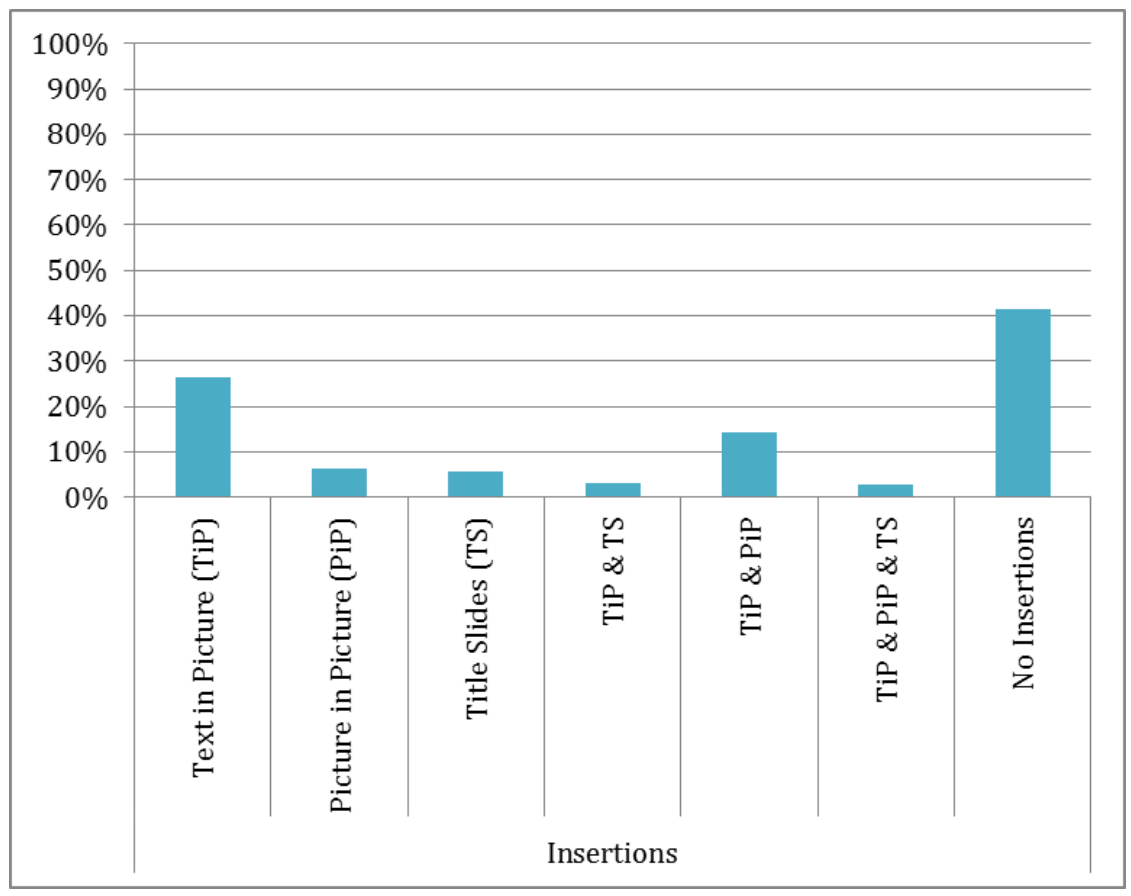

Figure 9: Additional FX being used in popular scientific web videos. Legend: text in picture (TiP), picture in picture (PiP), and title slides (TS).

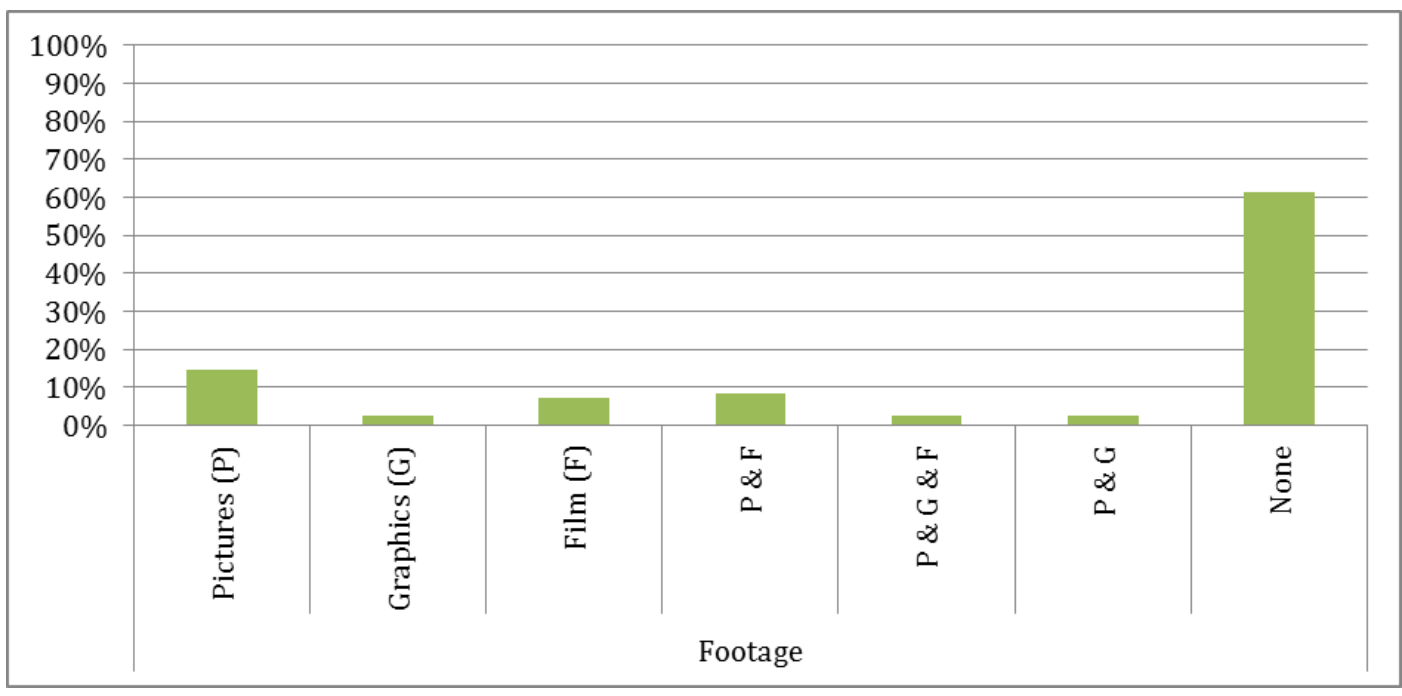

Figure 10: Kind of footage being used in the production of scientific web videos. Legend: pictures $(P)$, film $(F)$, graphics $(G)$.

- mostly in the video description, but also during the video itself as a copyright disclaimer. This use of external material is actually not always safe from the perspective of possible copyright infringement - a ubiquitous topic with online video material. As an example, in German law the appropriation of third-party material for film production is only possible under the protection of the quotation law. In case of doubt, the law can decline in favor of the copyright holder, even if the presumed lawbreaker is not making commercial use of the quoted footage. Other countries such as the United States of America are less restrictive about the use of footage, despite the regulations present in the Digital Millennium Copyright 
Act (see, for example, Laurence Lessig's deregulation efforts and the limitations on liability relating to online material, 17 U.S. Code $\S 512) .{ }^{11}$

Video editing and lighting techniques

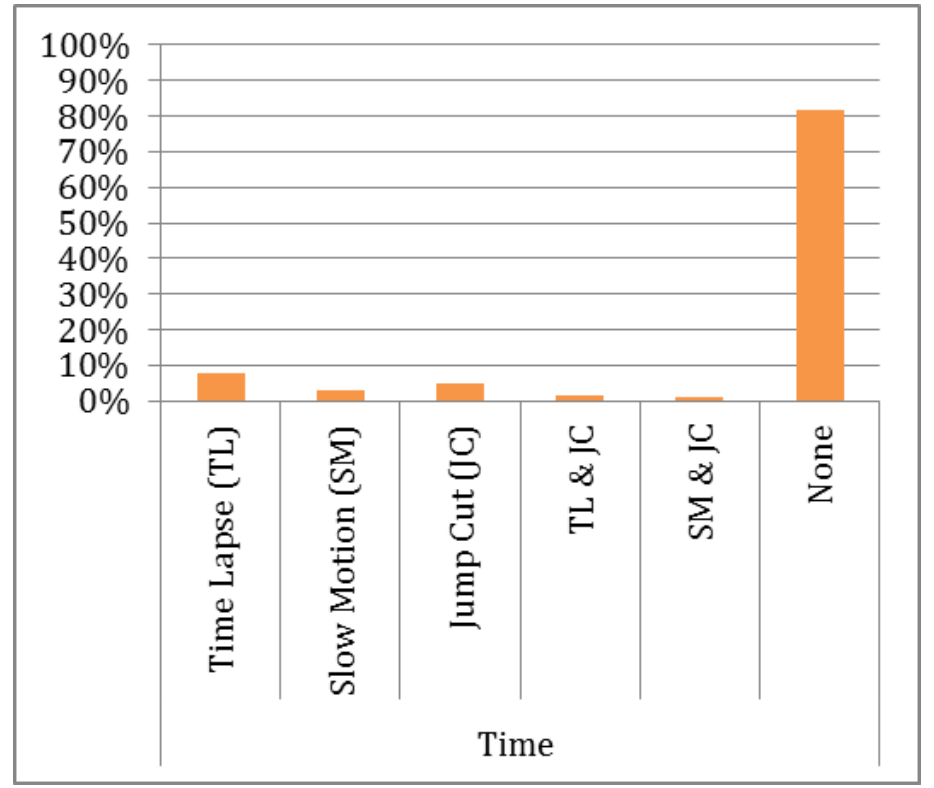

Figure 11: Advanced video editing techniques.

The use of advanced video editing techniques is moderate (Figure 11).

Nevertheless, Time Lapses $(8 \%)$ are mostly applied in order to match video material and narration for the sake of well-paced entertainment, Slow Motion sequences $(3 \%)$ are typical for visualizing details during an experiment (e.g. SlowMoGuys), and Jump Cuts (5\%) are mostly used in monologue videos for omissions and dramaturgic speed-up (e.g. matemarika86 and Bite Szi-zed).

An interesting fact is the average perception of manual white balance (Figures 12a and 12b). Manual white balance means a manual adjustment of color toning to achieve natural color reproduction, i.e. adjusting the color sensors of a video camera to the surrounding color temperature. By doing it manually, either prior to recording or in post-production, the camera operator can generally attain the best results without changing lighting conditions.

Every change in the lighting conditions, e.g. through an unexpected change of location, must be compensated for by adjusting the color balance so as to avoid a negative impact on the image quality. For that reason, the manual white balance (here $45 \%$ ) is a widely accepted standard among professionals. The auto white balance (here 29\%) allows an amateur video producer to concentrate on the story without worrying about the correct representation of colors, assuming one accepts some loss in quality. Using auto white balance leaves many color discrepancies during filming, even if the location remains constant, since people or objects with different colors entering into the scene can trigger an auto white balance action even if the surrounding color context has not substantially changed. For this

\footnotetext{
${ }^{11}$ http:/ / www.law.cornell.edu/uscode/text/17/512
} 


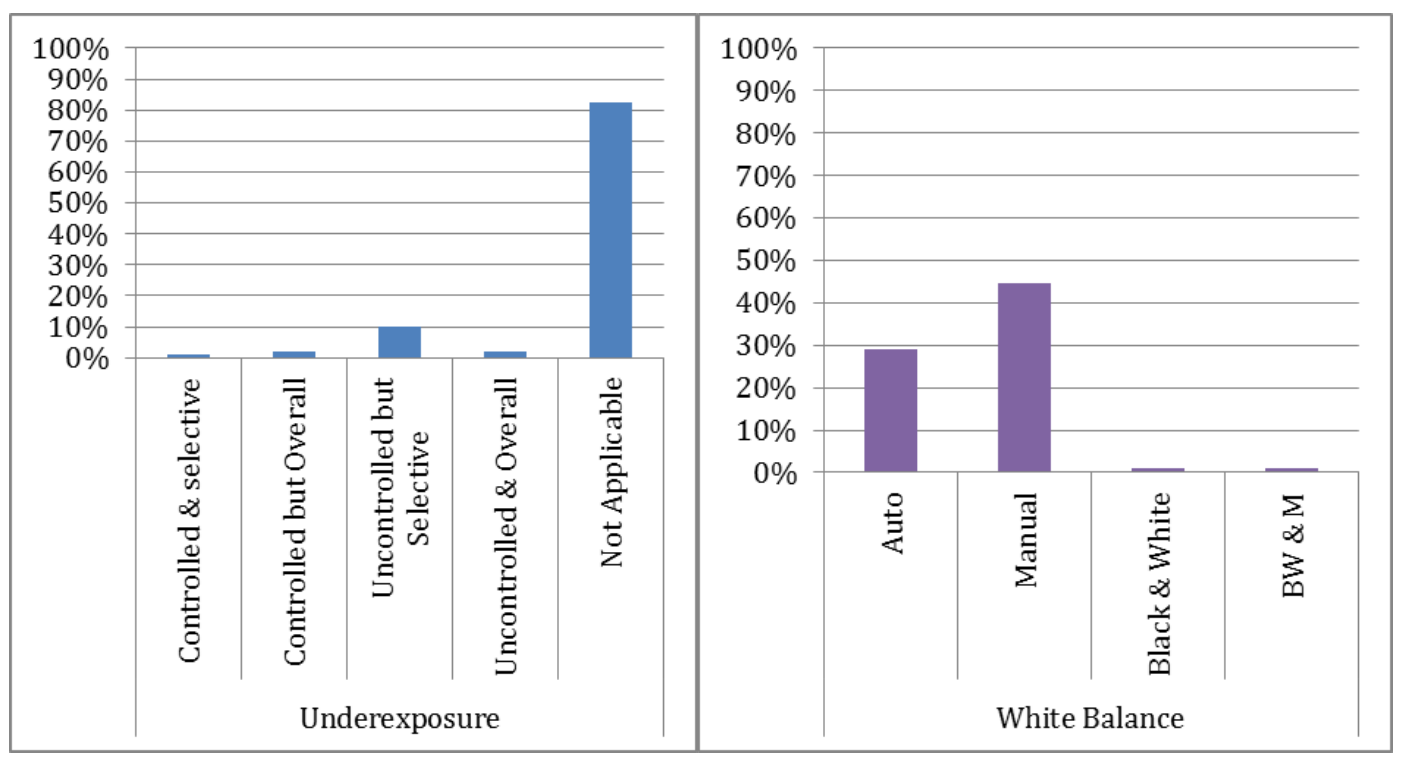

(a)

(b)

Figure 12: Lighting techniques and quality; type and quality of white balance.

reason, the average use of manual white balance perceived (48\%) is an indicator of the increase in the professionalism of visual productions for scientific web videos.

\section{Sound design}

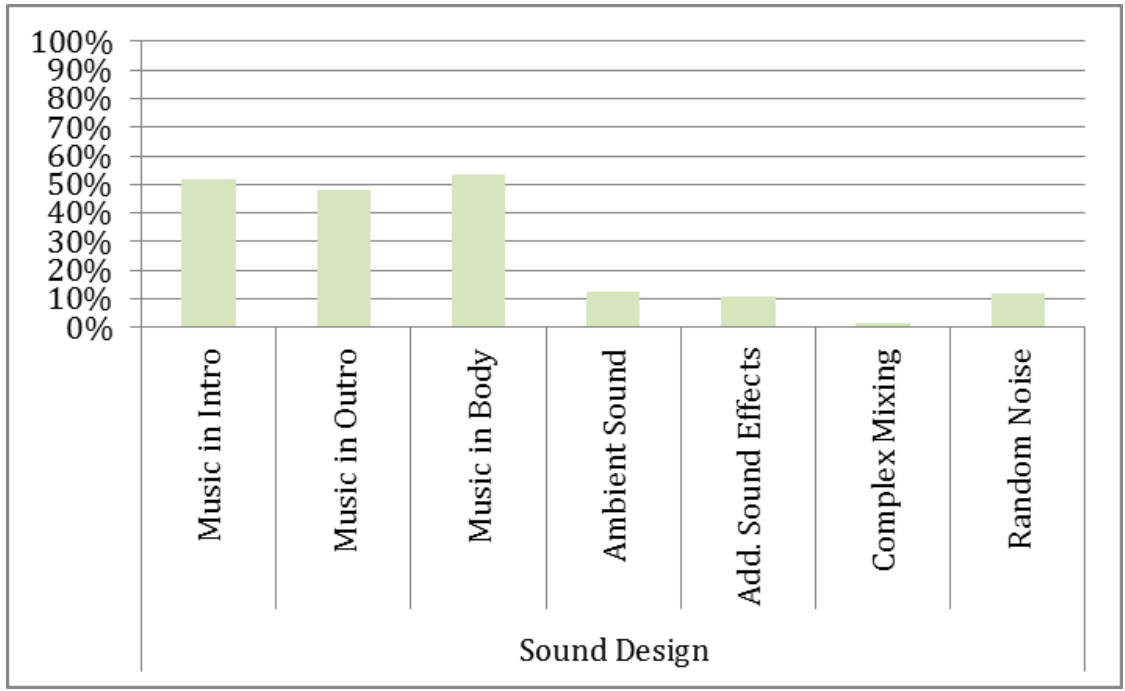

Figure 13: Sound design and distribution in film (indexical values).

As for sound design (Figure 13), more than half of the analyzed videos use some kind of accompanying music not only in the intro sequence (52\%) and the outro sequence $(48 \%)$ but also in the body of the film (54\%). Since the acoustic level of a movie conveys a very important part of the dramaturgy of a film, additional sound effects that support storyline and suspense action as well as complex mixing of sound are indicators of a high level of professionalism in the production of scientific web videos. Furthermore, music can mask unwanted accidental 
background noise in a video. In this regard, random noise (12\%) and ambient sounds (13\%) appear in similar proportions as additional sound effects $(11 \%)$, which denotes additional production effort at the level of sound design.

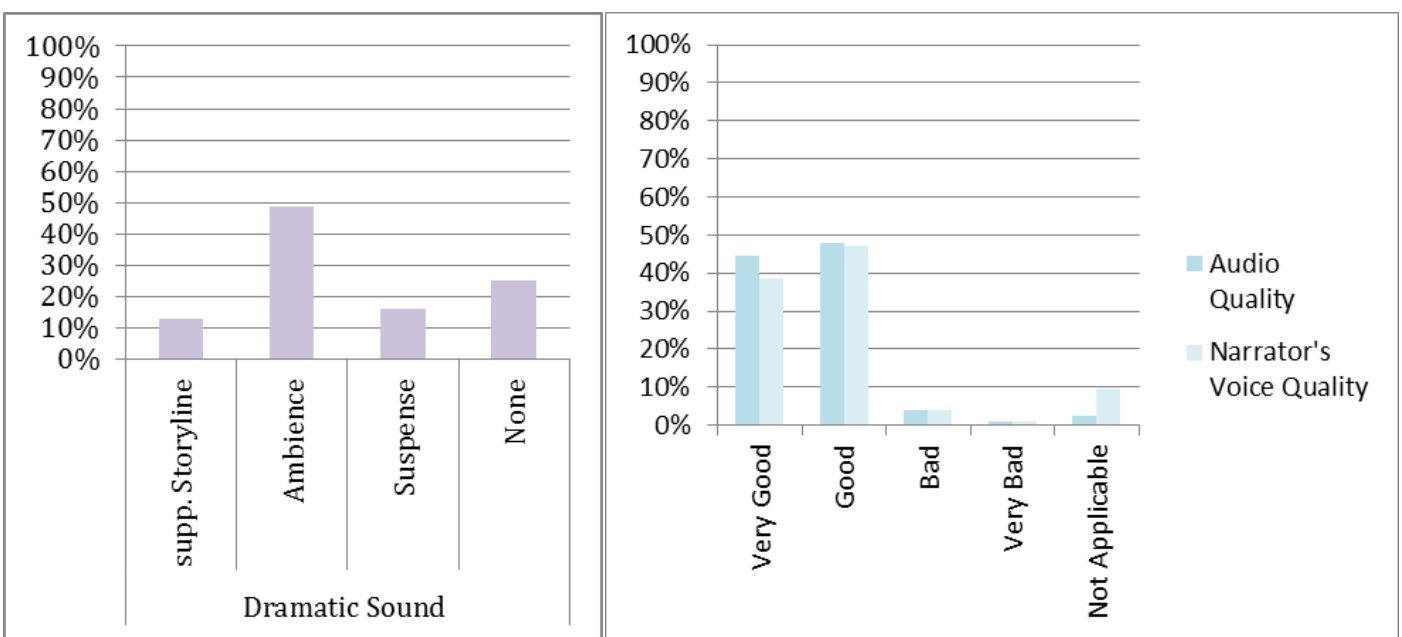

(a)

(b)

Figure 14: Sound design in the dramaturgic context, and audio quality.

Through the combination of music and sound effects in relation to dramatic measures, the impression of conscious or even professional sound editing becomes more noticeable: $13 \%$ of the videos use sound and music to support the storyline, and $16 \%$ of them use music and sound effects for the creation of suspenseful scenes (Figure 14a).

In addition, the average quality of the audio and of the narrator's voice (Figure $14 \mathrm{~b}$ ) are perceived as good ( $48 \%$ and $47 \%$ respectively) or very good ( $45 \%$ and $39 \%$ respectively).

The results suggest that popular science web videos are not always the most complex or profound ones. The productions of The Slow Mo Guys, for instance, are easy to understand and clearly structured: high-speed camera experiments with an entertaining but superficial presentation. Vsauce, as another example, is conceived as an electrifying monologue with explanatory footage and seemingly trivial themes that most people take for granted such as "What is yellow?" or "Why do we kiss?" Neither the complexity nor even the currency of the content but the way to communicate it seems to be the central point.

According to the commented data, we can distinguish the following main characteristics and tendencies of popular science videos:

a) Variety of (sub)genres.

There is a large variety of genres and subgenres - all of them produced as short videos. The most frequent "classic" genres being used are a) short documentary (e.g. Sixty Symbols) and b) animation (e.g. TED Ed), followed by far by the c) reportage (e.g. university productions). 
The videos we have classified within this genres, with the exception of reportages produced by universities, have some features that can be considered specific for internet video productions: they are short and entertaining, they have a clear explanatory and dramaturgic structure, in documentaries there is seldom a professional voice, the YouTuber and the actors use to speak in front of the camera, and intros and outros are oriented to increase the followers network.

There are also some emerging subgenres that deserve a separate mention. The main subgenres are: monologue (e.g. Vsauce); the overlapping category "questions \& answers", which can also be found as monologue or animation; whiteboard videos, i.e. live drawing (e.g. AsapScience) and live writing (e.g. Khan Academy); edited talks (e.g. TED Talks); portraits (e.g. FavScientist); or live experiments (e.g. TheSlowMoGuys).

The lack of some experimental formats such as fictional films, docudramas, or mockumentaries is interesting. This indicates the great focus of YouTubers on the communication of science in an entertaining but mostly very direct way. Nevertheless, there are also some videos with experimental character such as the animations of the UNSWTV channel from the University of New South Wales Australia. Essay films that focus on an unusual way of communicating and reflecting science in a political and societal context are also missing. Nevertheless, it should be mentioned, that there are very elaborate essay videos and experimental formats outside of YouTube, such as the online video platforms 94 Elements, Colliding Particles or Teslablog, but those examples are not present in our analysis for reasons of statistical consistency.

b) Moderate complexity of production.

In contrast to the popular assumption that YouTube videos are dilettante productions, we find enough evidence pointing to a certain level of professionalism, even if the use of professional or expensive recording techniques remains an exception. Nevertheless, we have discovered above-average use of some meaningful methods that point to a notable professionalism among the producers: e.g. the manual adjustment of white balance, the use of studio lights, some recurring special FX, and the common use of tripods for stable video recording.

While professional stabilizing equipment beyond tripods are hardly ever used, the results revealed that the amount and variety of shots resembled the distribution of shots being used in professional documentaries, where medium close-up (MCU) and extreme close-up (ECU) shots also are the favorite ones for science web videos (see point c) "High complexity of montage").

A good example of the professionalism in the production of popular science web videos is as mentioned the handling of white balance. Every change in the lighting conditions, e.g. through an unexpected change of location, must be compensated for by adjusting the color balance so as to avoid a negative impact on the image quality. For that reason, the manual white balance is a widely accepted standard among professionals. The auto white balance allows an amateur video producer to concentrate on the story without worrying about the correct representation of colors, assuming one accepts some loss in quality. Using auto white balance leaves many color discrepancies during filming, even if the location remains constant, since people or objects with different colors entering into the scene can trigger an 
auto white balance action even if the surrounding color context has not substantially changed. For this reason, the average use of manual white balance perceived (48\%) is an indicator of the professionalism of visual productions for popular science web videos.

c) High complexity of montage.

The amount and kind of cinematic techniques used in a video production can signify the level of professionalization with which a video was created. The examined visual and narrative strategies deployed give a good picture of the production complexity. Most of the analyzed videos demonstrate complex montage. The amount and variety of shots resembled the distribution of shots being used in professional documentaries, where medium close-up and extreme close-up shots also are the favorite ones for explanatory sequences. The high number and the variety of camera shots used for the elaboration of a story in more than $75 \%$ of the videos indicates intense post-production. Nevertheless, there are also web videos (18\%) that get by with a plan sequence or less than three shots (e.g. NurdRage). Most of them are live experiments with either sparse moderation or none at all. In general, the variety of shots is also typical for traditional TV productions. The use of close-ups for portraying people and unusual perspectives point out the importance of personal touch for this kind of video production in order to communicate scientific facts to the audience, and the experimental potential of science communication on YouTube. In addition, the use of external sound devices for good voice quality and the elaboration of dramatically efficient sound design are not unusual among many producers as we can guess based on the good to very good quality of the audio and narrator's voice (Figure 14b).

d) Storytelling experts.

The most remarkable feature and possibly the main characteristic of web video-related science communication is the focus of filmmakers on storytelling. Even if the main scientific topic is not a current one or is not perceived as very important for mankind, and even if the video quality is not the best, the power of an entertaining script can turn it into a viral event. This is why some channels are very successful despite certain formal production deficiencies or weaknesses such as unreliable automatic white balance (e.g. AsapScience), overexposure (e.g. SmarterEveryDay and Sixty Symbols), or minor sound problems. Even if our video corpus already consists of successful channels, in terms of popularity, good storytelling makes a difference. The art of storytelling relies on the use of dramaturgic means and narrative strategies that support an entertaining, intriguing and a pedagogical communication with the public (see Figures 3a to 4). This can be inferred from the number of takes, plot points and the combination of dramatic means such as eye catcher, in medias res or climax sequences. Videos with a studied dramaturgic structure, i.e. with an arc of suspense implying more than three plot points, have more visits than videos with a simple or almost non-existent dramaturgic structure. Behind every successful video we analyzed is a very well-told story in terms of an attractive combination of dramaturgic means, entertainment and explanatory value supported by the empathy of a charismatic presenter (e.g. in non-institutional short documentaries made by free YouTubers) and the originality of the visual narration (e.g. in animations). Videos that lack of one or more of these features such as 
reportages, interviews and portraits in TV style, mostly produced by universities and research institutions (e.g. ANUchannel and RMIT University), have also less subscribers and visits than free YouTubers.

e) Relevance of intro and outro sequences.

Most of the online videos we analyzed use advanced intro and outro sequences. These sequences are very important for both winning new followers and keeping them informed. Many intro sequences work as a dramatic part of the movie, and most of them are conceived as eye catchers becoming part of the dramaturgic means. Recognizable elements such as animated logos and jingle tones also form part of the composition in an intro. Subscribe links and calls as well as video recommendations are common in outro sequences in order to keep growing the network of followers.

f) The personal touch: building an emotional network.

The increasing professionalism of web video production is not so much to be found in the production techniques themselves as in the quality of movie montage and storytelling (i.e. in the narrative strategies and dramaturgic means). Most of the videos are low-budget productions, and some of them may have been made by amateurs, but by amateurs with a very good knack for storytelling and mise en scène. All short documentaries — including subcategories such as the monologue - follow to some extent the tradition of successful TV documentaries such as BBC documentaries and TV series with scientists as presenter. In that tradition, renowned scientists such as Carl Sagan or David Attenborough established a kind of personal connection with the public by explaining science directly to the camera with contagious enthusiasm. This is, for example, the dramaturgic and aesthetic core of the monologues and short documentaries made by Michael Stevens (Vsauce), Derek Muller (Veritasium) or Brady Haran (Sixty Symbols). While many universities continue using standard TV reportage or interviews, the new YouTube educators keep their networks growing by addressing their audience directly and communicating via comments and video responses to questions other users may have put forward.

It can be speculated that the dramatic means used in the analyzed videos are due to the specific viewing practices on YouTube. The audience's presumed short attention span and the almost endless offerings of other videos demand different techniques from content creators. ${ }^{12}$ Many of these creators rely on their charismatic personalities, addressing their viewers both as followers and dialogue partners.

In this study, 190 science web videos from different YouTubers (university productions, professionally produced and user-generated videos) were examined to identify the main typologies and difficulty levels of video production on the Internet. We identified a wide variety of genres and subgenres, a moderate complexity of production, and a high to very high complexity of montage and storytelling that points toward a notable professionalism in the production of

\footnotetext{
${ }^{12}$ As described in the Organizational Structure of YouTube, the platform focuses on videos shorter than ten minutes. Although this formal restriction was removed in 2010, only 32 of the analyzed YouTube videos were longer than that, despite the fact that all were uploaded after the removal of time limits.
} 
science web videos. Most of the analyzed videos have calculated intro and outro sequences with typical elements that foster community building. The search for maximum dissemination and popularity determines the style and structure of the videos, including very short but exciting intros, a very dynamic main section, and the calculated display of subscribe links and related material at the end of every video. But the most significant aspect is that most of these YouTubers and creative web video producers are storytelling experts. community and production context - toward a network analysis
Future research:

The research presented provides an initial description of the state of the art in an unmanageable and ever-changing field: the popular science web video in the world of online video production. Research on the typologies of online science videos has only just begun. The researchers' next goal is a survey of production context, types of video descriptions, and the specific YouTube recommendation cultures - e.g. which links are recommended where and why. We assume a logical and consequent interrelation among typologies and contextual aspects, and observe that the code book we have used already hints at most of this information. For the moment, we have opted for a separate discussion of the results for the sake of clarity, dividing them into identity-related characteristics on the one hand and contextual-environmental aspects on the other. Studying the production context in detail would go beyond the scope of the present publication, whose main purpose is an initial description of common science video typologies.

In our upcoming research, however, the correlation, causation, and comparison of production context with the kind of video production used will allow new insights into the nature of the video typologies already investigated. Indeed, in order to see the whole picture, information on scientific online video typologies should be enhanced by including information about the videos' production context and the recommendation culture they are a part of. In addition, a network analysis of the interrelations of the producers will also provide an insightful assessment of the remarkable diversity of producers as well as of the sheer dimensions of the phenomenon itself.

Acknowledgments The authors would like to thank Friederike Shymura, Klarissa Niedermeier, and Thi Hoai Thuong Truong for their assistance in watching the videos and collecting a large amount of the video data, as well as Kareem James Abu-Zeid, Silke Flörchinger, Alina Marktanner, Arnhilt Kuder and Jens Görisch for their helpful comments and editing, including some grammatical corrections to this paper. 
Appendix A.

Questionnaire for data collection and full list of analyzed videos
Table 1: Coding questionnaire.

Questionnaire for data collection on science web videos for the public

Information on the Video Channel (Important: Please doublecheck all data!)

Consecutive Number from Dataset: \#

Video Title:

Date:

Filled out by:

\begin{tabular}{|c|c|c|c|}
\hline \multicolumn{4}{|c|}{ Video: Design description } \\
\hline $\begin{array}{l}\text { Number of } \\
\text { actors } \\
\text { according to } \\
\text { gender }\end{array}$ & \multicolumn{3}{|l|}{$\begin{array}{l}\text { Female actor(s)/speakers: } \\
\text { Male actor(s)/speakers: }\end{array}$} \\
\hline Thumbnail & \begin{tabular}{|l} 
Picture from video \\
Edited picture
\end{tabular} & $\begin{array}{l}\text { Thumbnail } \\
\text { (description) }\end{array}$ & \\
\hline $\begin{array}{l}\text { Estimated age of } \\
\text { the actor(s) }\end{array}$ & 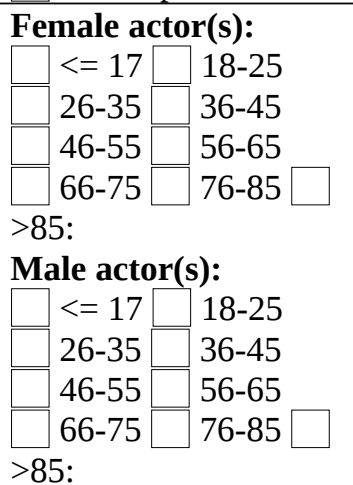 & $\begin{array}{l}\text { Location(s) } \\
\text { (multiple } \\
\text { choice) }\end{array}$ & $\begin{array}{l}\square \text { Indoor without stage } \\
\text { setting } \\
\square \text { Indoor with stage setting } \\
\square \text { Outdoor without stage } \\
\text { setting } \\
\square \text { Outdoor with stage setting } \\
\square \text { Other: }\end{array}$ \\
\hline $\begin{array}{l}\text { Camera work } \\
\text { (multiple choice) }\end{array}$ & 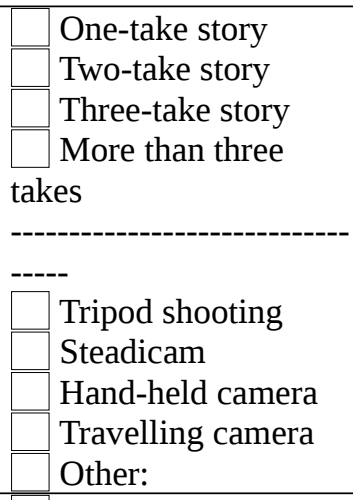 & $\begin{array}{l}\text { Shots used } \\
\text { (multiple } \\
\text { choice) }\end{array}$ & \begin{tabular}{|l|l|} 
& Extreme long shot \\
$\square$ & Long shot \\
$\square$ Medium long shot \\
$\square$ Medium shot \\
$\square$ Medium close-up \\
$\square$ Close-up \\
$\square$ Extreme close-up \\
$\square$ Unusual perspective/shot \\
$\square$ & Other:
\end{tabular} \\
\hline $\begin{array}{l}\text { Storyline } \\
\text { (multiple choice) }\end{array}$ & $\begin{array}{l}\text { First-person narrator } \\
\text { Third-person } \\
\text { narrator } \\
\text { Number of plot points: } \\
\square \text { Up to } 2 \text { plot } \\
\text { points } \\
\text { Up to } 4 \text { plot } \\
\text { points } \\
\text { More than } 4 \text { plot } \\
\text { points } \\
\text { Eye catcher in } \\
\text { opening }\end{array}$ & $\begin{array}{l}\text { Genre } \\
\text { (multiple } \\
\text { choice) }\end{array}$ & 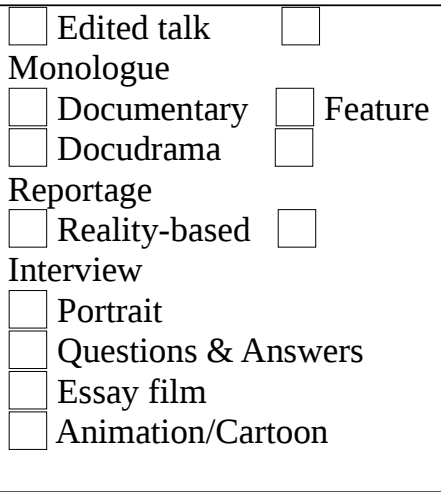 \\
\hline
\end{tabular}

Continued on the next page 
Table 1: Continued from the previous page.

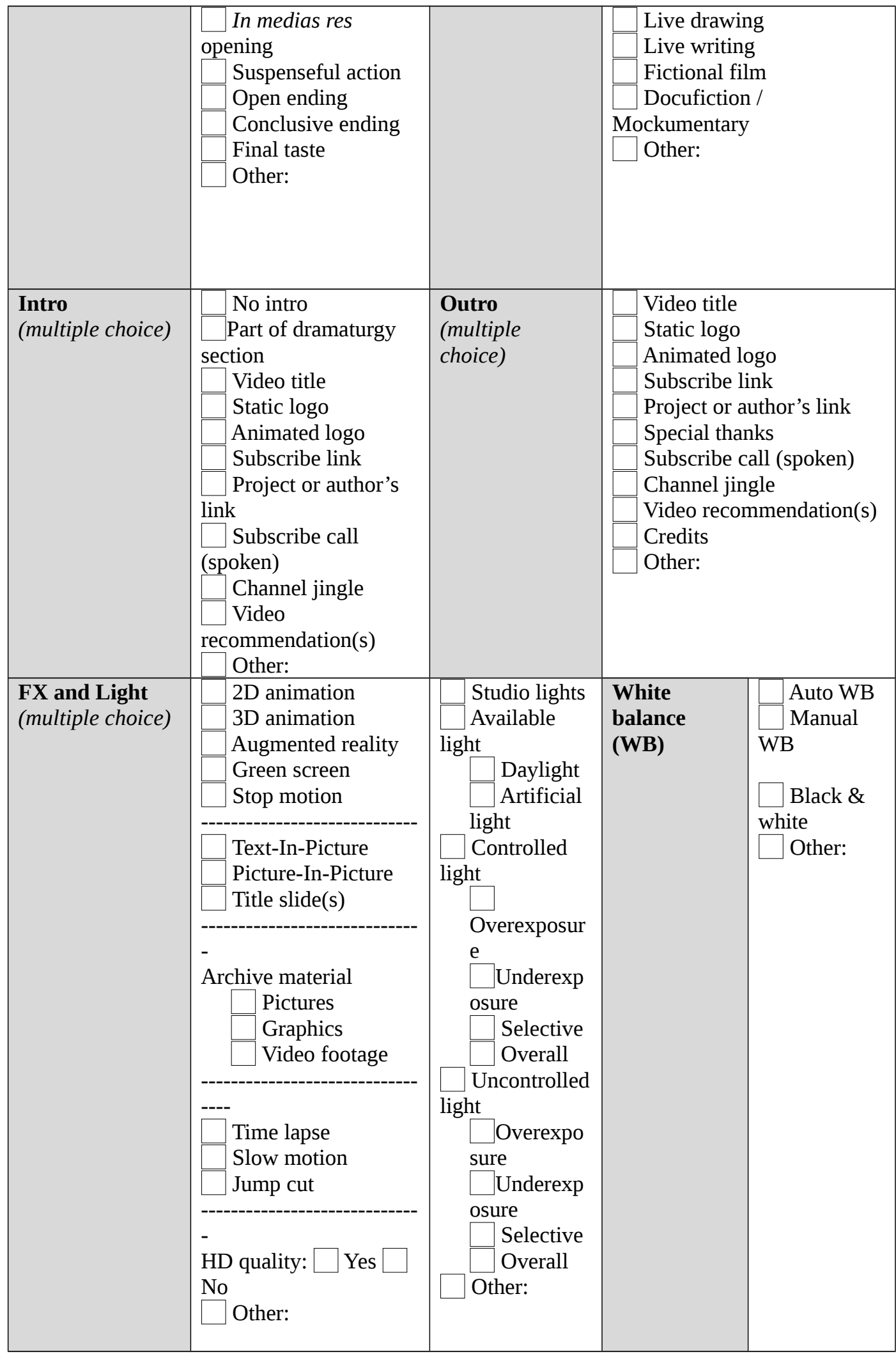

Continued on the next page 
Table 1: Continued from the previous page.

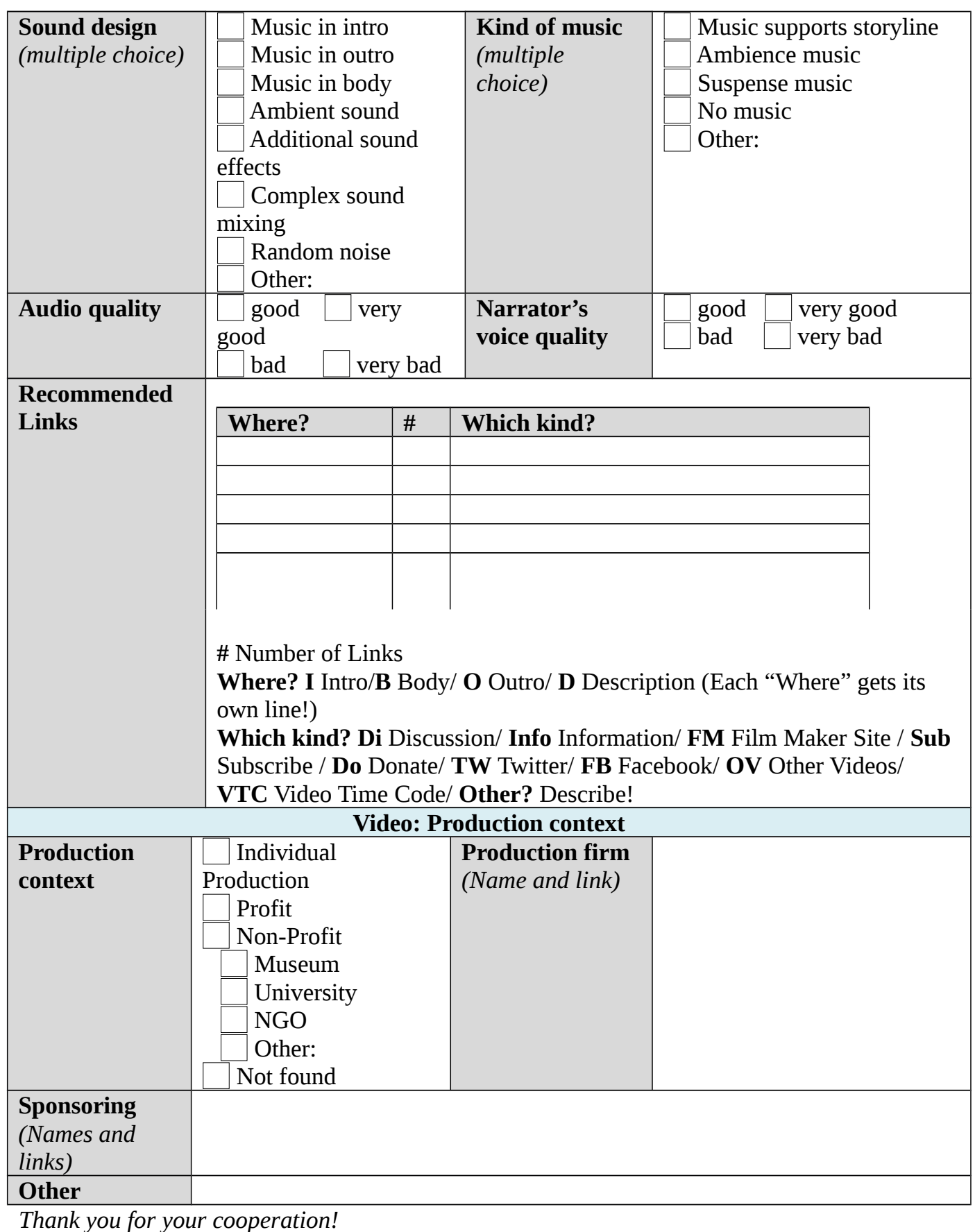


Table 2: Full List of 190 analyzed videos and 95 channels.

\begin{tabular}{|c|c|c|}
\hline Nr. & Channel & Video title \\
\hline 1 & asapSCIENCE & Which Came First — The Chicken or the Egg? \\
\hline 2 & asapSCIENCE & The Scientific Power of Teamwork \\
\hline 3 & Khan Academy & Basic Addition \\
\hline 4 & Khan Academy & Subtracting complex numbers \\
\hline 5 & MinutePhysics & Immovable Object vs. Unstoppable Force — Which wins? \\
\hline 6 & Minute Physics & How modern Light Bulbs Work \\
\hline 7 & NurdRage & Coke Can in Liquid Nitrogen \\
\hline 8 & NurdRage & Make an Iron Heart \\
\hline 9 & $\begin{array}{l}\text { Scientific American } \\
\text { Space Lab }\end{array}$ & How to Enter the Space Lab Competition \\
\hline 10 & $\begin{array}{l}\text { Scientific American } \\
\text { Space Lab }\end{array}$ & Behind the Scenes \\
\hline 11 & SciShow & The Truth About Gingers \\
\hline 12 & SciShow & Trouble in Bed: When Sleep Turns Against Us \\
\hline 13 & SpanglerScienceTV & Magic Sand — Sand that is Always Dry! \\
\hline 14 & SpanglerScienceTV & Lava Lamp - Cool Science Experiment \\
\hline 15 & Sixty Symbols & Putting your Hand on the LHC \\
\hline 16 & Sixty Symbols & The Sound of Atoms Bonding \\
\hline 17 & Smarter Every Day & How Houdini Dies (in Slow Motion) \\
\hline 18 & Smarter Every Day & Cold Hard Science. The Physics of Skating on Ice \\
\hline 19 & SpaceRip & Earth 100 Million Years from Now \\
\hline 20 & SpaceRip & Water Planet \\
\hline 21 & TED Ed & Questions no one knows the answer to \\
\hline 22 & TED Ed & Why do we cry? The three types of tears \\
\hline 23 & TED Talks & Tony Robbins: Why we do what we do \\
\hline 24 & TED Talks & $\begin{array}{l}\text { Mary Lou Jepsen: } \\
\text { Could future devices read images from our brain? }\end{array}$ \\
\hline 25 & Veritasium & World's Roundest Object \\
\hline 26 & Veritasium & Can you solve this? \\
\hline 27 & Vi Hart & Hexaflexagons \\
\hline 28 & Vi Hart & Cookie Shapes \\
\hline 29 & SickScience & Dry Ice Boo Bubbles \\
\hline 30 & SickScience & Power of Bleach \\
\hline 31 & Acchiappamente & $\begin{array}{l}2 \times 05 \text { - Disney e Coca-cola ti controllano? } \\
\text { [Messaggi subliminali }- \text { Psicologia] }\end{array}$ \\
\hline 32 & Acchiappamente & \#Acchiappamente - Stress buono o cattivo? \\
\hline 33 & Alberto Lori & Libertà di cambiare (psicologia quantistica) \\
\hline 34 & Alberto Lori & Il pensiero focalizzato (psico quantistica) \\
\hline 35 & ANUchannel & $\begin{array}{l}\text { Richard Dawkins and Lawrence Krauss: } \\
\text { Something from Nothing }\end{array}$ \\
\hline 36 & ANUchannel & A Conversation with Andrew Macintyre \\
\hline 37 & BozemanScience & A Tour of the Cell \\
\hline 38 & BozemanScience & The Brain \\
\hline 39 & $\begin{array}{l}\text { Canal Educatif } \\
\text { à la demande (CED) }\end{array}$ & Simulation d'entretien de recrutement \\
\hline 40 & $\begin{array}{l}\text { Canal Educatif } \\
\text { à la demande (CED) }\end{array}$ & L'art en Question 08: Carpaccio — Le Jeune Chevalier \\
\hline
\end{tabular}


Table 2: Continued from the previous page.

\begin{tabular}{|c|c|c|}
\hline Nr. & Channel & Video title \\
\hline 41 & Deep Sky Videos & Messier Objects \\
\hline 42 & Deep Sky Videos & Inside an Opening Telescope \\
\hline 43 & $\begin{array}{l}\text { La Educación } \\
\text { Prohibida }\end{array}$ & LEP - Archivos Abiertos \#01 - Carlos González \\
\hline 44 & $\begin{array}{l}\text { La Educación } \\
\text { Prohibida }\end{array}$ & LEP - Archivos Abiertos \#11 - Antonio Solórzano \\
\hline 45 & GeroMovie & DNA-Replication Biologie \\
\hline 46 & GeroMovie & Winkelarten \\
\hline 47 & ImbaTorben & Todesmilch Titten \\
\hline 48 & ImbaTorben & Die $5 A^{\prime}$ s - so bekommst du du jede Frau \\
\hline 49 & matemarika86 & $\begin{array}{l}\text { Non funziona la funzione!!! - Studio di funzioni e } \\
\text { dominio }\end{array}$ \\
\hline 50 & matemarika86 & $\begin{array}{l}\text { VIDEO INTERATTIVO Caccia al tesoro: Alla ricerca della } \\
\text { X perduta - Equazioni di primo grado intere }\end{array}$ \\
\hline 51 & Mental Floss & 50 Common Misconceptions \\
\hline 52 & Mental Floss & 27 Amazing Facts about Comics \\
\hline 53 & NASA JPL Videos & Mars Science Laboratory Curiosity Rover Animation \\
\hline 54 & NASA JPL Videos & What's Up for March 2014? \\
\hline 55 & The Slow Mo Guys & Giant 6ft Water Balloon \\
\hline 56 & The Slow Mo Guys & Airbag Deploying in Slow Mo \\
\hline 57 & NewScientist & Spray-on Clothing \\
\hline 58 & NewScientist & Cyborg Drummer creates Unique Beats \\
\hline 59 & Nucleus Medical & Birth: McRoberts Maneuver \\
\hline 60 & Nucleus Medical & Nucleus Custom Medical Animation Process \\
\hline 61 & PBS IdeaChannel & Are Bronies Changing the Definition of Masculinity? \\
\hline 62 & PBS IdeaChannel & $\begin{array}{l}\text { Does Twitch Plays Pokemon } \\
\text { Give You Hope for Humanity? }\end{array}$ \\
\hline 63 & RMIT University & How hydrogen engines work \\
\hline 64 & RMIT University & $\begin{array}{l}\text { Australia-India Research Centre } \\
\text { für Automation Software Engenieering }\end{array}$ \\
\hline 65 & Scientific American & Your Brain in Love and Lust \\
\hline 66 & Scientific American & Is Our Universe a Hologram? \\
\hline 67 & Storm & Amazing Upward Lightning! \\
\hline 68 & Storm & Extreme Dust Storm Takes Over Phoenix, Arizona 2011 \\
\hline 69 & foodskey & Being mean to broccoli \\
\hline 70 & foodskey & Phytoplasmas in Plants \\
\hline 71 & Unicoos & $\begin{array}{l}\text { Matriz inversa, traspuesta y adjunta } 2 \circ \mathrm{BACHI} \text { unicoos } \\
\text { matemáticas }\end{array}$ \\
\hline 72 & Unicoos & $\begin{array}{l}\text { BILLION = BILLON?? unicoos nosvemosenclase Face- } \\
\text { book compra Whatsapp }\end{array}$ \\
\hline 73 & Unisciel & Faire implose une canette \\
\hline 74 & Unisciel & Unisciel Select: numero 55 \\
\hline 75 & Universcience & FIV mode d'emploi \\
\hline 76 & Universcience & Herbier \#7 — on a une belle série de citrons \\
\hline 77 & UNSW TV & How to survive beach rip current \\
\hline 78 & UNSW TV & Why winds explain earth's surface warming slowdown \\
\hline 79 & CrashCourse & The Agricultural Revolution \\
\hline 80 & CrashCourse & Fate, Family, and Oedipus Rex \\
\hline
\end{tabular}


Table 2: Continued from the previous page.

\begin{tabular}{|c|c|c|}
\hline Nr. & Channel & Video title \\
\hline 81 & Computerphile & The Problem with Time \& Timezones \\
\hline 82 & Computerphile & EXTRA BITS - Installing Ubuntu Permanently \\
\hline 83 & MinuteEarth & Where Did Earth's Water Come From? \\
\hline 84 & MinuteEarth & Are any Animals Truly Monogamous? \\
\hline 85 & Numberphile & Why do YouTube views freeze at $301 ?$ \\
\hline 86 & Numberphile & Brussels Sprouts \\
\hline 87 & PeriodicVideos & Gold Bullion Vault — Periodic table of Videos \\
\hline 88 & PeriodicVideos & The world's greatest autograph book \\
\hline 89 & Vsauce & What if Everyone JUMPED at once? \\
\hline 90 & Vsauce & What is the Resolution of the Eye? \\
\hline 91 & The SpanglerEffect & Getting Ready for Guiness World Record Season 01 Ep.01 \\
\hline 92 & The SpanglerEffect & Flying Toilet Paper Season 02 Ep.19 \\
\hline 93 & CGPGrey & The Difference between the UK, GB and England \\
\hline 94 & CGPGrey & The Law You Won't Be Told \\
\hline 95 & Vlogbrothers & Giraffe Love and Other Questions ANSWERED \\
\hline 96 & Vlogbrothers & Is the American Dream Real? \\
\hline 97 & Quantum Fracture & ¿Queé es la Ciencia? \\
\hline 98 & Quantum Fracture & Uno de los Principios Maás Importantes del Univers \\
\hline 99 & MinutoDeFísica & Errores comunes en física \\
\hline 100 & MinutoDeFísica & $\mathrm{E}=\mathrm{mc}^{2}$ está Incompleta \\
\hline 101 & Ever Salazar & Calculando Areas \\
\hline 102 & Ever Salazar & $\begin{array}{l}\text { (not so) Cold Fun: } \\
\text { Qué hacer cuando no está tan frio afuera }\end{array}$ \\
\hline 103 & The Spirit Science & Spirit Science $1 \sim$ Thoughts \\
\hline 104 & The Spirit Science & Spirit Science 22 (part 4) Source Energy \\
\hline 105 & ScienceBob & Science Bob's Crazy Foam Experiment \\
\hline 106 & ScienceBob & Exploding Pumpkins on Jimmy Kimmel Live \\
\hline 107 & ouLEarn & Shakespeare: Original Pronunciation \\
\hline 108 & ouLEarn & Maryam Bibi - Unlikely Leaders (2/5) \\
\hline 109 & Euronews Knowledge & World's smallest atomic clock \\
\hline 110 & Euronews Knowledge & Can Earthquakes Bring Life? Do You Know? \\
\hline 111 & Naked Scientists & $\begin{array}{l}\text { How does DNA fingerprinting work? Naked Science } \\
\text { Scrapbook }\end{array}$ \\
\hline 112 & Naked Scientists & Main Alu II re-uploaded \\
\hline 113 & Educatina & Síntesis de proteínas - Biología - Educatina \\
\hline 114 & Educatina & Patrones de medición - Física - Educatina \\
\hline 115 & FavScientist & Gregor Mendel — My Favourite Scientest \\
\hline 116 & FavScientist & Ignaz Semmelweis - My Favourite Scientist \\
\hline 117 & Depfisicayquimica & Agua que no cae / The water doesn't fall down \\
\hline 118 & Depfisicayquimica & Cubo que no se derrama II \\
\hline 119 & Brusspup & Amazing Anamorphic Illusions \\
\hline 120 & Brusspup & Cool Rolling Illusion Toy! How to \\
\hline 121 & Jörn Loviscach & 22.6.1 Stetigkeit \\
\hline 122 & Jörn Loviscach & P3 Datumsdifferenz in Tagen mit Embedded Controller \\
\hline 123 & ChemExperimentalist & How to make sulfuric acid \\
\hline 124 & ChemExperimentalist & $\begin{array}{l}\text { Make Calcium Hydroxide - } \\
\mathrm{Ca}(\mathrm{OH})^{2} \text { from Plaster of Paris }\end{array}$ \\
\hline
\end{tabular}


Table 2: Continued from the previous page.

\begin{tabular}{|c|c|c|}
\hline Nr. & Channel & Video title \\
\hline 125 & Abenteuer Wissen & Star Trek: Wie funktioniert Impuls- und Warpantrieb \\
\hline 126 & Abenteuer Wissen & Timescapes: Learning to Fly — die Welt im Zeitraffer \\
\hline 127 & Welt der Wissenschaft & Animaterie und Relativität \\
\hline 128 & Welt der Wissenschaft & Wie einzigartig ist der Mensch? \\
\hline 129 & Welt der Physik & Was ist ein schwarzes Loch? \\
\hline 130 & Welt der Physik & Monsterwellen im Labor \\
\hline 131 & WissensMagazin & Der tiefste Blick ins All \\
\hline 132 & WissensMagazin & $\mathrm{E}=\mathrm{mc}^{2}-$ Die Äquivalenz von Masse und Energie \\
\hline 133 & TheSimpleMaths & Exponentialfunktion und Logarithmus \\
\hline 134 & TheSimpleMaths & $\begin{array}{l}\text { Gebrochenrationale Funktionen - Nullstellen, Defini- } \\
\text { tionsbereich... }\end{array}$ \\
\hline 135 & Fisica Total & $\begin{array}{l}\text { Física Total - Aula } 07-\text { vetor }- \\
\text { Vetores e operações vetoriais }\end{array}$ \\
\hline 136 & Fisica Total & $\begin{array}{l}\text { ENEM em AÇÃO - Física \#01 } \\
\text { (principais habilidades cobradas na prova de...) }\end{array}$ \\
\hline 137 & Canal Ciência e Ficção & $\begin{array}{l}\text { Jurassic Park parte } 1 / 2- \\
\text { É possível clonar dinossauro? - Ciência e Ficção }\end{array}$ \\
\hline 138 & Canal Ciência e Ficção & $\begin{array}{l}\text { Star Wars Episódio VII - O } \\
\text { Que Esperar? - Ciência e Ficção }\end{array}$ \\
\hline 139 & Manual do Mundo & Congele água em 1 seg — o segredo \\
\hline 140 & Manual do Mundo & $\begin{array}{l}\text { Revelação da Mágica dos ladrões de galinha } \\
\text { (mágica fácil revelada) }\end{array}$ \\
\hline 141 & Quirkology & 10 More Amazing Science Stunts (3) \\
\hline 142 & Quirkology & The Tube of Mystery \\
\hline 143 & NASA eClips & Real World: Space Shuttle Thermal Protection System \\
\hline 144 & NASA eClips & Real World: Comet Quest \\
\hline 145 & It's Okay To Be Smart & The Science of Snowflakes \\
\hline 146 & It's Okay To Be Smart & How The Elements Got Their Names \\
\hline 147 & $\begin{array}{l}\text { Bill Nye the Science } \\
\text { Guy }\end{array}$ & Atoms \\
\hline 148 & $\begin{array}{l}\text { Bill Nye the Science } \\
\text { Guy }\end{array}$ & Climate \\
\hline 149 & TheBadAstronomy & Snow that doesn't melt! Is it a government conspiracy? \\
\hline 150 & TheBadAstronomy & Glory from an Airplane window \\
\hline 151 & EEVblog & World's Most Expensive Hard Drive Teardown \\
\hline 152 & EEVblog & Voltech PM300 Power Analyser Teardown \\
\hline 153 & NobelPrize & Interview with 1994 Laureate in Economics John Nash \\
\hline 154 & NobelPrize & $\begin{array}{l}\text { Ben Bernanke speaks about the } 2011 \\
\text { Laureates in Economic Science }\end{array}$ \\
\hline 155 & SmithsonianChannel & Titanoboa: Monster Snake: Titanoboa vs. T-Rex \\
\hline 156 & SmithsonianChannel & $\begin{array}{l}\text { Secrets of the Third Reich: } \\
\text { This Video Exposes Hitler's Secret Illness }\end{array}$ \\
\hline 157 & ScienceChannel & $\begin{array}{l}\text { Jumping Jack Ants vs. Huntsman Spider/ } \\
\text { Monster Bug Wars }\end{array}$ \\
\hline 158 & ScienceChannel & $\begin{array}{l}\text { The Time Scientists Thought } \\
\text { They Saw The Real Death Star }\end{array}$ \\
\hline 159 & Stevebd1 & Nuclear Fusion \\
\hline 160 & Stevebd1 & A Sudden Multiplication of Planets \\
\hline
\end{tabular}


Table 2: Continued from the previous page.

\begin{tabular}{|c|c|c|}
\hline Nr. & Channel & Video title \\
\hline 161 & techNyouvids & Critical Thinking Part 1: A Valuable Argument \\
\hline 162 & techNyouvids & Nanotechnology Part 2: Nanoproperties \\
\hline 163 & Explainity & Euro-Krise leicht erklärt \\
\hline 164 & Explainity & Korruptionsbekämpfung leicht erklärt \\
\hline 165 & Doktor Allwissend & Warum alle Apple lieben \\
\hline 166 & Doktor Allwissend & Warum wir Vorurteile brauchen \\
\hline 167 & Getty Museum & The Mummification Process \\
\hline 168 & Getty Museum & Ansel Adams: Visualizing a photograph \\
\hline 169 & Bite Szi-zed & Caffeine \\
\hline 170 & Bite Szi-zed & Reindeer Eyes \\
\hline 171 & Nature Video & Lego Antikythera Mechanism \\
\hline 172 & Nature Video & The Beginning of Everything \\
\hline 173 & Brainscoop & Where My Ladies At? \\
\hline 174 & Brainscoop & The Two-Faced Calf, Pt. I \\
\hline 175 & $\begin{array}{l}\text { Wahre Verbrechen. } \\
\text { Wahre Stories }\end{array}$ & Doktor Allwissends ABC der Kriminalität \#Y wie Yakuza \\
\hline 176 & $\begin{array}{l}\text { Wahre Verbrechen. } \\
\text { Wahre Stories }\end{array}$ & Fritz Haarmann — SERIAL KILLERS \#WV.WS \\
\hline 177 & $\begin{array}{l}\text { Northwestern } \\
\text { NewsCenter }\end{array}$ & The Incredible Robot Fish \\
\hline 178 & $\begin{array}{l}\text { Northwestern } \\
\text { NewsCenter }\end{array}$ & James Agaard, A Lifetime Wildcat \\
\hline 179 & DLRde & DLR crawler robot meets Justin and Hand-Arm-System \\
\hline 180 & DLRde & How Philae got ist name \\
\hline 181 & TU Muenchen & Typisch TUM \\
\hline 182 & TU Muenchen & $\begin{array}{l}\text { TUM Ambassador Professor Patrick Dewilde } \\
\text { about the importance of networks for scientific thinking }\end{array}$ \\
\hline 183 & $\begin{array}{l}\text { European Space } \\
\text { Agency, ESA }\end{array}$ & First-ever live 3D video stream from space \\
\hline 184 & $\begin{array}{l}\text { European Space } \\
\text { Agency, ESA }\end{array}$ & Sentinel-1A rides into space on a Soyuz \\
\hline 185 & Kurzgesagt & Fracking explained: opportunity or danger \\
\hline 186 & Kurzgesagt & Engineering \& Curiosity \\
\hline 187 & Hybrid Libraryian & World's 10 Most Mysterious Pictures Ever Taken \\
\hline 188 & Hybrid Libraryian & Earth's 10 Most Important Events in History \\
\hline 189 & Cambridge University & Memories of old awake \\
\hline 190 & Cambridge University & $\begin{array}{l}\text { Putting our House in Order: William Kent's Designs } \\
\text { for the Houses of Parliament }\end{array}$ \\
\hline
\end{tabular}

\section{References}

Alexa (2015). Web Traffic Analysis of YouTube.com. URL:

http://www . alexa.com/siteinfo/youtube. com (visited on 18th March 2015).

Backinger, C. L., Pilsner, A. M., Augustson, E. M., Frydl, A., Phillips, T. and

Rowden, J. (2010). 'YouTube as a source of quitting smoking information'.

Tobacco Control 20 (2), pp. 119-122. DOI: 10.1136/tc.2009.035550.

Bordwell, D. and Thompson, K. (2006). Film Art: An Introduction. New York, U.S.A: McGraw-Hill.

Bucchi, M. (1998). Science and the Media. New York, U.S.A.: Routledge. 
Bucchi, M. and Trench, B., eds. (2008). Handbook of Public Communication of Science and Technology. New York, U.S.A.: Routledge.

Hartley, J. (2009). 'Uses of YouTube - Digital Literacy and the Growth of Knowledge'. In: YouTube. Online Video and Participatory Culture. Ed. by J. Burgess and J. Green. Cambridge, U.K.: Polity Press, pp. 126-143.

Jenkins, H. (2006). Convergence Culture: Where Old and New Media Collide. New York, U.S.A.: New York University Press.

Keelan, J., Pavri-Garcia, V., Tomlinson, G. and Wilson, K. (2007). 'YouTube as a Source of Information on Immunization: A Content Analysis'. JAMA: Journal of the American Medical Association 298 (21), pp. 2481-2484. DOI: 10.1001/jama.298.21.2482.

Keen, A. (2007). The Cult of the Amateur: How Today's Internet is Killing Our Culture and Assaulting Our Economy. London, U.K.: Nicholas Brealey, p. 5.

Korte, H. (1999). Einführung in die Systematische Filmanalyse. Berlin, Germany: Erich Schmidt Verlag.

Lo, A. S., Esser, M. J. and Gordon, K. E. (2010). 'YouTube: A gauge of public perception and awareness surrounding epilepsy'. Epilepsy $\mathcal{E}$ Behavior 17 (4), pp. 541-545. DOI: 10.1016/j . yebeh.2010.02.004.

Lovink, G. (2011). 'Society of the Query: The Googlization of our Lives'. In: Networks without a Cause. A Critique of Social Media. Cambridge, U.K.: Polity Press, pp. 146-157.

Marek, R. (2013). Understanding YouTube. Über die Faszination eines Mediums. Bielefeld, Germania: Transcript.

Pariser, E. (2011). The Filter Bubble: What the Internet Is Hiding from You. New York, U.S.A.: Penguin Press.

Quantcast (2015). Web Traffic Analysis of YouTube.com. URL: https://www . quantcast.com/youtube.com (visited on 18th March 2015).

Robertson-von Trotha, C. Y. and Muñoz Morcillo, J., eds. (2012). Öffentliche Wissenschaft und Neue Medien. Die Rolle der Web 2.0-Kultur in der Wissenschaftsvermittlung. Karlsruhe, Germany: KIT Scientific Publishing.

Sampson, M., Cumber, J., Li, C., Pound, C. M., Fuller, A. and Harrison, D. (2013). 'A systematic review of methods for studying consumer health YouTube videos, with implications for systematic reviews'. PeerJ 1, e147. DOI: 10.7717/peerj. 147. PMID: 24058879.

Sood, A., Sarangi, S., Pandey, A. and Murugiah, K. (2011). 'YouTube as a Source of Information on Kidney Stone Disease'. Urology 77 (3), pp. 558-562. DOI: 10.1016/j. urology . 2010.07.536.

Steinberg, P. L., Wason, S., Stern, J. M., Deters, L., Kowal, B. and Seigne, J. (2010). 'YouTube as source of prostate cancer information'. Urology 75 (3), pp. 619-622. DOI: $10.1016 / j$.urology . 2008.07.059.

Steinmetz, R. (2002). Film- und Fernsehästhetik in Theorie und Praxis. Leipzig, Germany: Verein zur Förderung der Medienforschung und -ausbildung e.V.

Welbourne, D. and Grant, W. J. (2015a). 'What makes a popular science video on YouTube'. The Conversation. URL: http://theconversation . com/what-makes-a -popular-science-video-on-youtube-36657 (visited on 18th March 2016).

Welbourne, D. J. and Grant, W. J. (2015b). 'Science communication on YouTube: Factors that affect channel and video popularity'. Public Understanding of Science, pp. 1-14. DOI: 10.1177/0963662515572068.

Yang, W. and Qian, Z. (December 2011). 'Understanding the Characteristics of Category-Specific YouTube Videos'. CMPT771 COURSE PROJECT. 
Jesús Muñoz Morcillo is junior researcher at ZAK - Center for Cultural and General Studies. He is coordinator of the Public Science and New Media projects at ZAK and has recently finished his PhD on art techniques in the media art work of Stephan von Huene at Karlsruhe University of Arts and Design (Staatliche Hochschule für Gestaltung Karlsruhe, HfG). He was coordinator of the DFG (German Research Foundation) funded project "InsideScience" (2010-2012) and has conducted research on e-Installation together with the Intelligent Sensor-Actuator-Systems Laboratory (ISAS) at KIT. For further Information see: http://www.zak.kit.edu/english/media_and_science.php.

E-mail: jesus.morcillo@kit.edu.

Klemens Czurda is scientific assistant at ZAK. He has a Bachelor's Degree in Sociology and is currently studying Fotography and Media Art at the Karslruhe University of Arts and Design (HfG). E-mail: klemens.czurda@partner.kit.edu.

Prof. Dr. Caroline Y. Robertson-von Trotha is director of ZAK. She studied sociology, philosophy, and history in Heidelberg and Karlsruhe and holds a Ph.D. in sociology. She habilitated in Karlsruhe in 2004 and is member of curatorship at the Institute for Cultural Politics of the Culture-Political Association of Germany. Robertson-Trotha was associated member of the scientific advisory committee at the European Institute for Comparative Culture Research ECarts. She is coordinator of the German network of the Anna Lindh Foundation, member of the Culture Committee of the German UNESCO Commission, spokeswoman of the KIT competence area "Technology, Culture, and Society", and editor of three scientific book series. E-mail: zak@zak.kit.edu.

\section{How to cite}

Muñoz Morcillo, J., Czurda, K. and Robertson-von Trotha, C. Y. (2016). 'Typologies of the popular science web video'. JCOM 15 (04), A02. 